University of Louisville

ThinkIR: The University of Louisville's Institutional Repository

Electronic Theses and Dissertations

$4-2010$

\title{
Numerical simulation of a flat back airfoil for wind turbine applications.
}

Matthew Fuller

University of Louisville

Follow this and additional works at: https://ir.library.louisville.edu/etd

\section{Recommended Citation}

Fuller, Matthew, "Numerical simulation of a flat back airfoil for wind turbine applications." (2010).

Electronic Theses and Dissertations. Paper 471.

https://doi.org/10.18297/etd/471

This Master's Thesis is brought to you for free and open access by ThinkIR: The University of Louisville's Institutional Repository. It has been accepted for inclusion in Electronic Theses and Dissertations by an authorized administrator of ThinkIR: The University of Louisville's Institutional Repository. This title appears here courtesy of the author, who has retained all other copyrights. For more information, please contact thinkir@louisville.edu. 

APPLICATIONS

\author{
By \\ Matthew Fuller \\ B.S. Eng., University of Louisville, 2009
}

A Thesis

Submitted to the Faculty of the

University of Louisville

J.B. Speed School of Engineering

in Partial Fulfillment of the Requirements

for the Professional Degree

\title{
MASTER OF ENGINEERING
}

Department of Mechanical Engineering

April 2010 



\title{
NUMERICAL SIMULATION OF A FLAT BACK AIRFOIL FOR WIND TURBINE APPLICATIONS
}

\author{
Submitted by: \\ Matthew Fuller \\ A Thesis Approved On \\ (Date)
}

by the Following Reader and Examination Committee:

Dr. Yongsheng Lian, Thesis Director

Dr. R. Eric Berson

Dr. Geoffrey Cobourn 


\section{ACKNOWLEDGEMENTS}

The author would like to thank his advisor Dr. Yongsheng Lian for all the guidance

and tutelage in learning the CFD process, defining clear project goals, and preparing this report. 


\begin{abstract}
Wind energy provides an attractive power source as an alternative to fossil fuels because it is abundant, clean, and produces no harmful emissions. To extract more energy from the wind we need to increase the wind turbine size. However, the increase in size has begun to reach a limit in terms of material composition and structural stability. To quell the trend of increasing size in wind power systems alternative wind turbine blade designs are investigated and evaluated to increase power production and efficiency of present size machines. Flat back airfoils have been proposed for the inboard region of large wind turbine blades because they provide structural and aerodynamic advantages. In this work we will investigate the aerodynamic performance of flat back airfoils with computational fluid dynamics techniques. To reduce the drag and noise inherent from the blunt trailing edge, a splitter plate with varying lengths is added to the trailing edge of the airfoils. Comparisons are made with experimental data. Excellent agreement is achieved with the measurements. Our numerical simulations show that the flat back airfoil can increase lift production as much as $20 \%$. The splitter can effectively reduce drag by as much as $20 \%$ and tonal noise by as much as $20 \mathrm{~dB}$.
\end{abstract}


TABLE OF CONTENTS

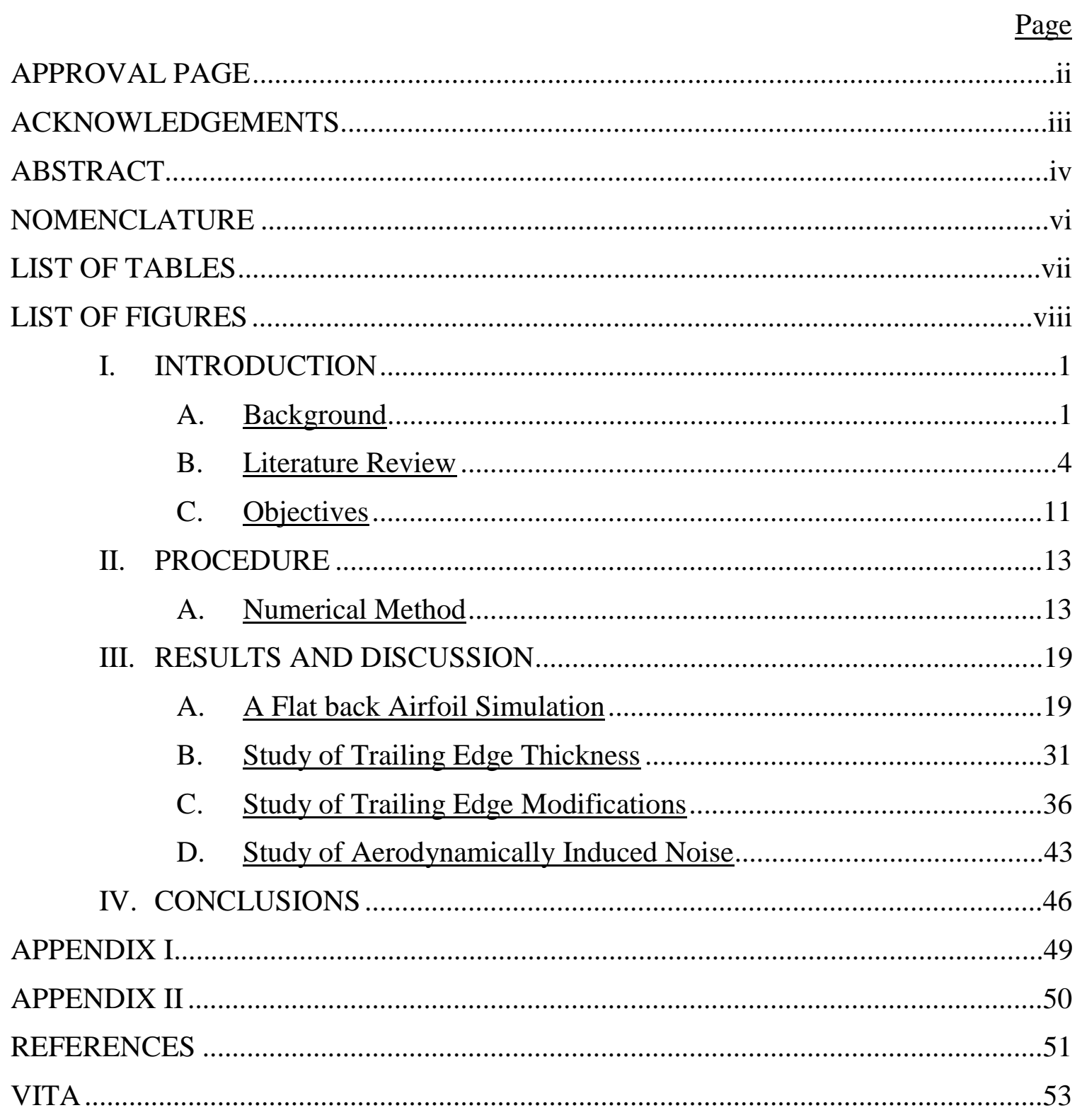




\title{
NOMENCLATURE
}

\author{
Farfield $=$ Free stream of fluid simulation domain \\ $\mathrm{C}=$ Chord length of airfoil \\ $\mathrm{Y}^{+}=$Non dimensional distance for wall bounded flow
}




\section{LIST OF TABLES}

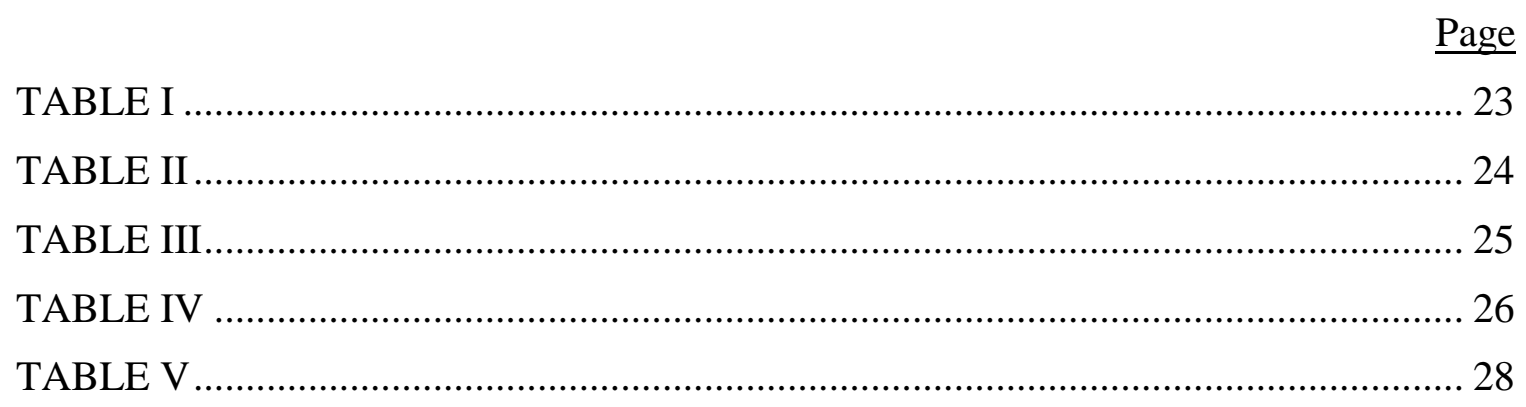




\section{LIST OF FIGURES}

Page

FIGURE 1 - Horizontal axis wind turbine ............................................................ 4

FIGURE 2 - HAWT size to power relationship (van Dam, 2009) ................................... 6

FIGURE 3 - Examples of wind turbine blade sections (Griffith, 2009) ........................... 7

FIGURE 4 - Blunt trailing edge airfoil geometry (Berg et al, 2008) .............................. 9

FIGURE 5 - Lower trailing edge vortex formation (van Dam 2009) .............................. 10

FIGURE 6 - TU Delft DU 97-W-300 blunt trailing edge airfoil .................................. 16

FIGURE 7 - Fluent boundary conditions for fluid simulation.................................... 18

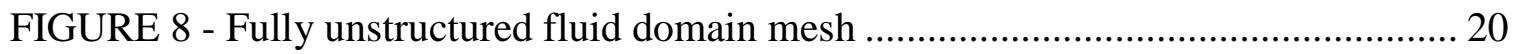

FIGURE 9 - Detail view of fully unstructured airfoil mesh ...................................... 20

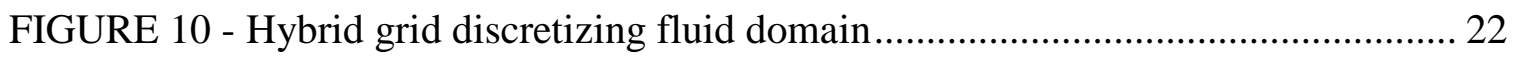

FIGURE 11 - Structured grid circumferential spacing sensitivity mesh ....................... 23

FIGURE 12 - Coefficient of lift versus angle of attack two equation model .................. 26

FIGURE 13 - Two and three equation k- $\omega$ model lift coefficient comparison ................ 27

FIGURE 14 - Vorticity contours, a. Unstructured grid/turbulent scheme, b. Unstructured grid/transition scheme, c. Hybrid grid/turbulent scheme, d. Hybrid grid/transition scheme,

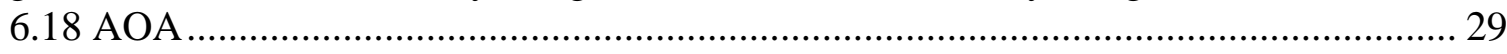

FIGURE 15 - Airfoil surface coefficient of pressure values numerical vs. experimental,

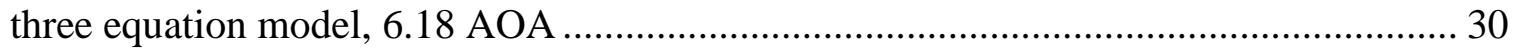

FIGURE 16 - Unstructured mesh for airfoil trailing edge width $10 \%$ of chord ............... 32

FIGURE 17 - Airfoil trailing edge thickness lift coefficient comparison ....................... 32

FIGURE 18 - Lift-drag polar plot for $1.74 \% \mathrm{C}$ and 10\% C trailing edge thickness, 2-10

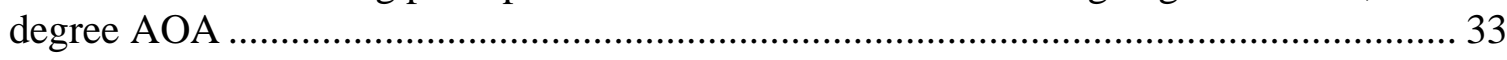

FIGURE 19 - Instantaneous vorticity contours for $10 \% \mathrm{C}$ trailing edge thickness airfoil, $6.18 \mathrm{AOA}$ 35

FIGURE 20 - Airfoil surface coefficient of pressure values $1.74 \% \mathrm{C}$ vs. $10 \% \mathrm{C}$ trailing edge thickness, 6.18 AOA 35 
FIGURE 21 - Unstructured grids, a. Flatback airfoil with $2 \%$ chord wise splitter plate length, b. Flatback airfoil with $10 \%$ chord wise splitter plate length

FIGURE 22 - Lift-drag polar plot for varying splitter length from 2-10 degree AOA, fully

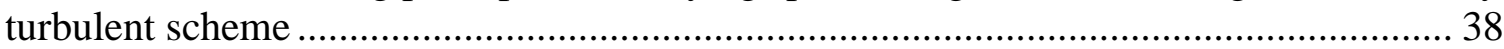

FIGURE 23 - Lift-drag polar plot for varying splitter length from 2-10 degree AOA, free transition scheme 39

FIGURE 24- Vorticity contours, two equation model, a. 2\% chord splitter length, b. 5\% chord splitter length, c. $7.5 \%$ chord splitter length, d. 10\% chord splitter length, 6.18

AOA.

FIGURE 25 - Pressure coefficient contours with streamlines, two equation model, 6.18

AOA, a. flatback airfoil, b. $10 \%$ chord splitter plate length

FIGURE 26- Pressure coefficient contours with streamlines, three equation model, 6.18 AOA, a. flatback airfoil, b. $10 \%$ chord splitter plate length

FIGURE 27 - Airfoil surface coefficient of pressure values flatback vs. flatback w/ 10\%

C splitter length, 6.18 AOA ................................................................................. 42

FIGURE 28 - Aero-acoustic simulation sound pressure level receiver location .............. 44

FIGURE 29 - Low frequency band sound pressure level, 6.18 AOA ............................ 45 


\section{INTRODUCTION}

\section{$\underline{\text { A. Background }}$}

In this day of natural resource scarcity and environmental considerations, renewable energy is in demand. All sources from solar to wind are being investigated for their validity as a source of human energy. The natural resources humans have become intimately dependent on in the past century are rapidly being depleted. According to the Science Application International Corporation Report (Campbell, 2009) industrialized nations will experience increased cost of production of goods and services, rapid inflation, and soaring unemployment due to the peak and sharp decline of oil production that is imminently approaching. Exiting a century of relatively inexpensive energy costs and abundant supplies of non-renewable resources, the population is relatively unaware that these resources will, by the next century, be very scarce. To cope with these realities many are turning to renewable clean sources of energy to continue to power the modern world. Solar power is at the forefront of much research due to the seemingly limitless supply of energy from the sun. Solar collectors are used to capture radiated energy from the sun and, using this natural energy, heat liquid to produce kinetic energy that we as humans can harness. A 2005 study found that the 159 million $\mathrm{m}^{2}$ of solar collector area 
contributed $111 \mathrm{GW}_{\text {th }}$ to the world's energy consumption (Kaygusuz, 2009). With this capacity arise issues in the form of pollution formed in the construction of solar systems and the depletion of non-renewable resources in the construction of the supporting equipment (Kaygusuz, 2009). The drawback to the harness of renewable natural resources in the form of photovoltaic cells is the necessity to allocate large plots of land which can affect the natural habitat. Additionally the fluid used in the production of photovoltaic cells and batteries is caustic and toxic to the environment and poses the risk of spills (Kaygusuz, 2009). In his paper on the environmental impacts of the solar energy systems Kaygusuz references the International Energy Agency in predictions of world primary energy demand increasing by as much as $60 \%$ by the year 2030 . These projected trends suggest that energy related $\mathrm{CO}_{2}$ emissions will increase as well by $1.7 \%$ per year. More than a third of world power consumption is due to heating. Solar heating technologies are a viable solution to this demand. Care must be exercised though in the handling and maintenance of solar thermal systems as the likelihood of environmental impacts due to improperly handled support materials is significant. Solar thermal systems utilize coolant to transfer energy and maintain safe operating conditions within the system. This coolant could contain glycol, nitrates, or sulfates which can all pose problems to the ecosystem if not properly disposed of (Kaygusuz, 2009).

Hydro power is another source of clean generated energy. From "small hydro" projects in newly reformed Afghanistan (Hallett, 2009) to large hydro power projects in remote parts of China (McNally et al, 2009) the energy of moving water is being harnessed for power production. As with solar power, the cycle of the earth being heated 
by the sun helps to perpetuate the transference of energy to water in the form of evaporation to a higher potential level. Despite the seeming simplicity of constructing dams and power generation stations the problems with hydro power are the scarcity of large rivers and the difficulties associated with transmitting energy to landlocked parts of the world. Further, hydro power facilities can have large environmental impacts by changing the environment and affect land use and natural habitats in the dam area.

Wind turbines harness the kinetic energy of the earth's atmosphere and transform this energy to first mechanical and then electrical energy for human consumption. The process by which this takes place utilizes moving airfoils that interact with the natural movement of air. Air movement is a result of the radiant energy produced by the sun and absorbed by the earth. If humans were able to in some way utilize this huge scale movement of the earth's atmosphere for our own energy requirements the benefit would be tremendous. A limitless supply of energy lasts as long as the sun shines. The human attempt to tap this global energy source is in the form of rotating wings known as wind turbines. 


\section{B. Literature Review}

The total amount of economically extractable power available from the wind is considerably more than present human power use from all sources (Hurley, 2008). An estimated 72 terawatt (TW) of wind power on the Earth potentially can be commercially viable (The Global Wind Resource). Currently humans are responsible for about 15 TW average global power consumption from all sources in 2005.

It has been speculated that nearly 10 million megawatts are at any one time available in the earth's atmosphere due to wind (Balat, 2009). Yet the largest problem with wind power is its reliance on the variability of the wind. At present wind power is rapidly becoming competitive to power production from coal with an average cost per kilowatt hour of 3-7 cents. Wind power at present accounts for $0.55 \%$ of the world electricity production (Balat, 2009).

The most common type of wind turbine is the horizontal axis wind turbine. It is configured such that three to four blades are attached to a horizontally mounted axle which rotates to generate electricity. FIGURE 1 below provides a common layout.

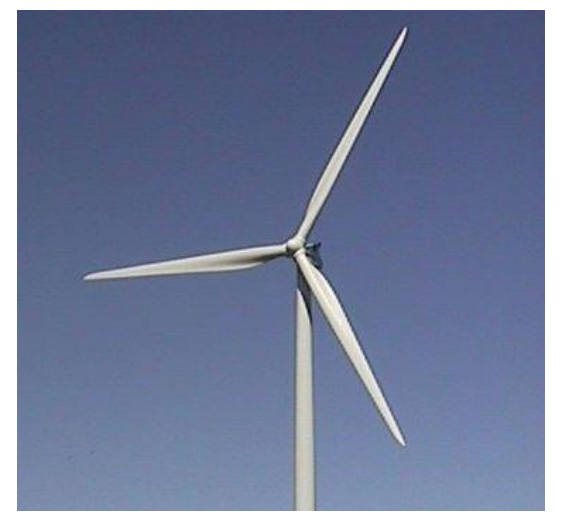

FIGURE 1 - Horizontal axis wind turbine 
The first mode in which the wind turbine interacts with the wind is through the blades. The blades of a wind turbine are located 60 to 100 meters high to be better placed in the stream of the moving atmosphere (Balat, 2009). The blades of the wind turbine are attached to a horizontally oriented shaft which rotates as the blades spin, hence the distinction "Horizontal Axis Wind Turbine". This horizontal shaft is geared to an electrical generator that uses moving magnets and wire to produce electricity. Generator design, gearing, and fabrication all take a backseat to the necessity for the blades of the turbine to convert the natural kinetic energy of the atmosphere to mechanical energy. The blades of the wind turbine after all are the sole positively interacting component with the wind. Wind turbine blade design is an active field of study comprising airfoil design, blade structural analysis, and blade material analysis. A rapidly advancing study within this field is the integration and validation of new non-standard airfoil designs for the improvement of blade efficiency and cost. Issues such as blade noise, blade integrity, and blade performance are all areas for improvement. Rotor size at present is between 70 and $100 \mathrm{~m}$ in rotating diameter with production of 1-5 MW of power (Ashwill, 2009). The goal for further research is to optimize blade design to quell the continual growth in turbine size and expense. At present material choice and construction is a hugely important part of wind turbine design simply because they are becoming so massive. A limit is being reached in terms of material capacity and strength. FIGURE 2 shows the progression of wind turbine size over the last two decades. 


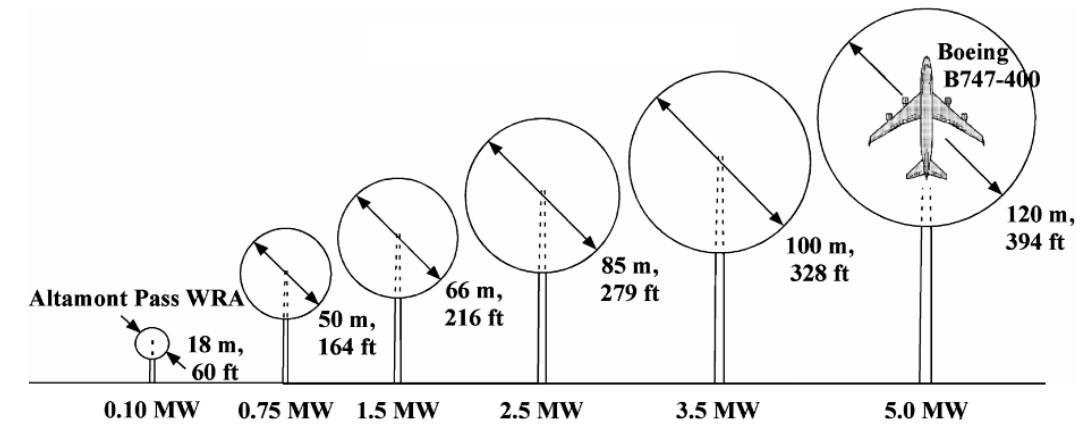

FIGURE 2 - HAWT size to power relationship (van Dam, 2009)

It is to be expected that with increased power demands wind turbines will have to increase in size. What is unexpected and undesirable is the cubic rate that blade mass is expanding given the squared rate of power increase. A given blade length is proportionate to mass ${ }^{3}$ while only proportionate to power $^{2}$ (van Dam, 2009). This presents a problem in terms of blade performance and durability. Material structural limits are being reached due to the gravity associated with larger turbine blades. The use of longer blades to achieve higher power output is losing the battle to manufacturing costs, expected efficiencies, and durability standards. Three often investigated areas for improvement are in turbine blade structural design for size considerations, blade flow and load control devices, and blade profile design for increased power and efficiency (van Dam, 2009).

The typical turbine blade is a hollow airfoil with an I-beam like inner frame to distribute working loads (Griffith, 2009). The outer profile of the blade is shaped from balsa or foam both of which are easily formed and inexpensive. Fiberglass layers compose the remaining shell of the blade. FIGURE 3 illustrates this material construction. Turbine efficiency is directly tied to initial cost hence the use of less exotic 
materials. As the blades of a wind turbine experience constantly changing loading and stresses, strength is required in all degrees of freedom. Researchers at Sandia National Laboratory have experimented with adding carbon fiber to high stress areas of the blades along with off-axis fibers to help with twist bending (Griffith, 2009).

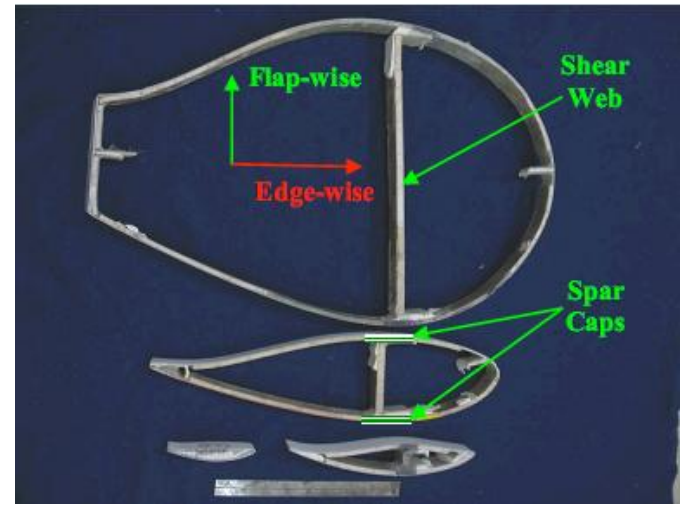

FIGURE 3 - Examples of wind turbine blade sections (Griffith, 2009)

A second approach to combat the negative impacts large blades impart to wind turbines is the advancing use of passive and active control on the blades themselves. Researchers at University of California Davis (van Dam, 2009) have been studying the use of both passive and active controls on turbine blades to increase the efficiency of existing blades while reducing the stress and loadings the blade would normally experience. As opposed to dealing directly with the size and mass of blades this approach centers on controlling even very large blades such that their design limits will never be exceeded in operation. Passive techniques include installing vortex generators and gurney flaps to the trailing edge of blades (van Dam, 2009). These vortex generators provide increased lift coefficient to very thick airfoils when used on the suction side. Active control of blades is seen in the concept of micro tabs installed at the trailing edge 
of the blade. These active devices have been shown to increase lift coefficient of the airfoil and can be controlled to maximize power output regardless of wind conditions.

A third approach to alleviate the massive size requirements of large wind turbine blades is the use of alternative airfoil designs. Thick airfoils are desired to increase the section modulus of the large turbine blades and improve durability without compromising material properties. In the first $40 \%$ of the span of a blade from the root it has been proposed to thicken the trailing edge of the airfoil shape to increase strength of the blade near the hub. Unfortunately very thick airfoils are prone to poor aerodynamic performance. Due to surface contamination, the boundary layer laminar to turbulent transition can occur very near to the leading edge. To attempt to remove the sensitivity to premature transition the airfoils are usually equipped with a blunt trailing edge (Winnemöller et al, 2007). The advantages to using a blunt trailing edge airfoil design are best summed up by The Sandia National Laboratories Blade System Design Study (Laird et al, 2004) in that flat back airfoils, which are designed by thickening the sharp trailing edge equally about the camber line of the blade. FIGURE 4 illustrates the method by which blunt trailing edge airfoils are created from sharp trailing edge airfoils. Their study showed that a flat back airfoil can increase lift, increase trailing edge strength, increase resistance to performance degradation due to blade soiling, and decrease manufacturing costs (Berg et al, 2008). However all this comes at the expense of increased drag and increased noise due to flow separation at the trailing edge. 


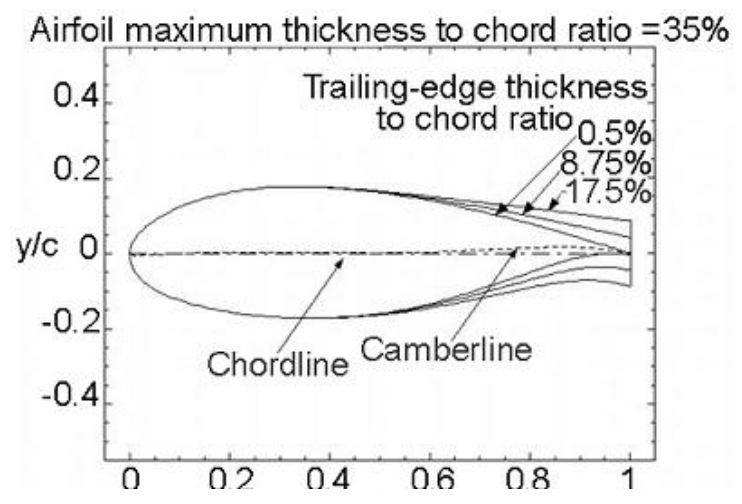

FIGURE 4 - Blunt trailing edge airfoil geometry (Berg et al, 2008)

Acoustical properties of blunt trailing edge airfoils have been investigated experimentally by Sandia National Laboratories to quantify the increase in noise as compared to a sharp trailing edge airfoil. It was found that at a Reynolds number of 3 million a traditional DU-97-W300 sharp trailing edge airfoil produced a sound pressure level of $77 \mathrm{~dB}$ while a DU-97-W300 airfoil with 10\% chord trailing edge thickness produced a sound pressure level of $100 \mathrm{~dB}$. Interestingly, the addition of a splitter plate to the center of the trailing edge equal to the width of the trailing edge reduced sound pressure level to $88 \mathrm{~dB}$ (Berg et al, 2008). These pressure levels all occurred in the range of 100-200 Hz which is at the level that will carry long distances and resemble a roaring from the turbine. Obviously it can be seen that through the addition of trailing edge modifications the negative aspects of the blunt trailing edge airfoil can be overcome in order to reap the benefits of increased strength and increased lift.

Lift characteristics have been found to be favorable for thick bodied blunt trailing edge airfoils as opposed to thick bodied sharp trailing edge airfoils. Thicker trailing edge airfoils benefit from reduced premature boundary layer transition and produce higher lift 
than thick bodied sharp trailing edge airfoils (Winnemöller et al, 2007). However, the formation of unsteady vortex shedding negatively affects the total lift to drag ratio of the blunt trailing edge airfoils. The large face of the trailing edge shows an adverse pressure gradient which allows vortices to form immediately after the trailing edge. According to Winnemöller (Winnemöller et al, 2007) vortices tend to form at the lower trailing edge which leads to a flow deceleration on the upper surface and a flow acceleration on the lower surface. This condition promotes drag and lowers the lift to drag ratio. van Dam provides a computational illustration of this trailing edge vortex formation in FIGURE 5.

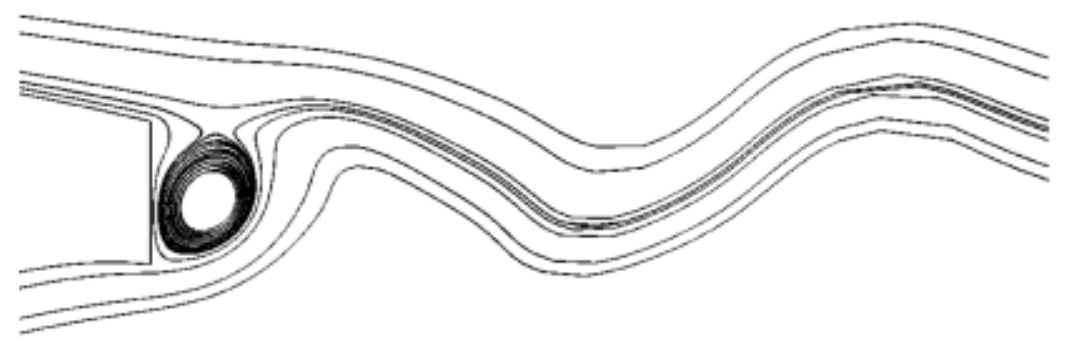

FIGURE 5 - Lower trailing edge vortex formation (van Dam 2009)

Researchers from the Georgia Institute of Technology have attempted to characterize this vortex inducing unsteady flow around the trailing edge of the flat back airfoil and characterize the emission of noise from the shed vortices using numerical simulations. A detached eddy simulation (DES) method is used. The DES method is composed of the Reynolds Averaged Navier Stokes method in the near wall regions of the flow field and the Large Eddy Simulation away from the wall regions to resolve the largest of energetic eddies (Stone et al 2009). This research utilizes both structured and unstructured meshing techniques. All simulations were run with a Reynolds number of $3 \times 10^{6}$ and a mixture of transition and fully turbulent models were used. Research findings were that 
the numerical predictions for lift coefficient are all within the experimental range measured in the Virginia Polytechnic Institute and State University wind tunnel. Although the two dimensional numerical simulations almost unanimously over predict drag coefficient by nearly $100 \%$. This trend is not displayed when using a three dimensional simulation (Stone et al 2009). The researchers also have shown that the addition of trailing edge treatments in the form of a splitter plate increase the lift to drag ratio by 15 to $20 \%$ (Stone et al 2009).

The noise produced from the vortex shedding at the trailing edge of the airfoil can be quantified as proportional to the mean square of the lift fluctuation produced by the shedding of vortices (Stone et al 2009). The research again suggested that two dimensional fluid simulation over predicted experimental farfield sound pressure levels due to the stronger lift fluctuation predicted by the two dimensional flow. The addition of the splitter plate to the trailing edge of the airfoil was shown to reduce the peak sound level by about 4 decibels (Stone et al 2009).

\section{Objectives}

The objective of this research is to investigate the aerodynamics of the flat back airfoil. Specifically the effect of a blunt trailing edge on blade performance will be investigated through numerical simulation to validate numerical predictions with known experimental results. The impact of trailing edge thickness on aerodynamic performance will be characterized and presented. Additionally the performance effects of the addition 
of a trailing edge modification in the form of a splitter plate will be investigated The scope of the project involves preprocessing the airfoil design, using a numerical solver to simulate the flow, and post-processing the results to characterize blade performance. 


\section{PROCEDURE}

\section{A. Numerical Method}

The software used to study the blunt trailing edge airfoils is the Ansys Fluent version 12.1 fluid solver. This tool provides the user with a full complement of Navier Stokes equation solvers. Turbulence modeling in the form of one, two, and three equation models is supported as well as both compressible and incompressible flow.

The Reynolds Averaged Navier Stokes (RANS) equations are solved for incompressible flow using a Boussinesq approach which relates the Reynolds stresses incurred by averaging the flow equations to the mean velocity gradients. This approach requires the determination of the turbulent viscosity. Closure of the RANS equations requires a solution for the turbulent viscosity. The turbulence models chosen to close the RANS equations describing flow about the wind turbine blade section are the two equation $k-\omega$ model and three equation $k-\omega-k_{l}$ transition model. The two equation $k-\omega$ model is based upon the Wilcox $k-\omega$ model (Wilcox, 2006) which has been shown to be in close agreement with measurements for far wakes, mixing layers, as well as plane, round, and radial jets. It is therefore applicable to wall-bounded flow as well as free shear flows. This model is an empirical model that solves transport equations for 
turbulent kinetic energy $(k)$ and specific dissipation rate $(\omega)$. The two transport equations for this model are shown below

$$
\begin{gathered}
\frac{\partial}{\partial t}(p k)+\frac{\partial}{\partial x_{i}}\left(p k u_{i}\right)=\frac{\partial}{\partial x_{j}}\left(\Gamma_{k} \frac{\partial k}{\partial x_{j}}\right)+G_{k}-Y_{k}+S_{k} \\
\frac{\partial}{\partial t}(p \omega)+\frac{\partial}{\partial x_{i}}\left(p \omega u_{i}\right)=\frac{\partial}{\partial x_{j}}\left(\Gamma_{\omega} \frac{\partial \omega}{\partial x_{j}}\right)+G_{\omega}-Y_{\omega}+S_{\omega}
\end{gathered}
$$

where $G_{k}$ and $G_{\omega}$ represent the turbulent kinetic energy generation and generation of $\omega$ respectively, $\Gamma_{k}$ and $\Gamma_{\omega}$ represent the effective diffusivity of $k$ and $\omega$ respectively, $Y_{k}$ and $Y_{\omega}$ represent the dissipation of $k$ and $\omega$ respectively due to the turbulence, and $S_{k}$ and $S_{\omega}$ are user specified turbulent kinetic energy and specific dissipation source terms. This model assumes the free shear flow is fully turbulent and requires the specification of boundary conditions for the turbulent kinetic energy $(k)$ and specific dissipation $(\omega)$.

The three equation $k-\omega-k_{l}$ transition model will be used to simulate the effect a lowturbulence free shear flow has upon the turbine blade section at a high Reynolds number. This model will naturally predict the transition from laminar to turbulent flow along the blade section. The three transport equations that are solved are the turbulent kinetic energy $\left(k_{t}\right)$, laminar kinetic energy $\left(k_{l}\right)$, and dissipation, or the inverse turbulent time scale, $(\omega)$. These transport equations are defined as 


$$
\begin{gathered}
\frac{D k_{T}}{D t}=P_{K_{T}}+R+R_{N A T}-w k_{T}-D_{T}+\frac{\partial}{\partial x_{j}}\left[\left(v+\frac{\alpha_{T}}{\alpha_{k}}\right) \frac{\partial k_{T}}{\partial x_{j}}\right] \\
\frac{D k_{L}}{D t}=P_{K_{L}}-R-R_{N A T}-D_{L}+\frac{\partial}{\partial x_{j}}\left[v \frac{\partial k_{L}}{\partial x_{j}}\right] \\
\frac{D_{\omega}}{D_{t}}=C_{\omega 1} \frac{\omega}{k_{T}} P_{k_{T}}+\left(\frac{C_{\omega \mathrm{R}}}{f w}-1\right) \frac{\omega}{k_{T}}\left(R+R_{N A T}\right)-C_{\omega 2} \omega^{2}+C_{\omega 3} f_{\omega} \alpha_{T} f_{W}^{2} \frac{\sqrt{k_{T}}}{d^{3}}+ \\
\frac{\partial}{\partial x_{j}}\left[\left(v+\frac{\alpha_{T}}{\alpha_{\omega}}\right) \frac{\partial_{\omega}}{\partial x_{j}}\right]
\end{gathered}
$$

where $k_{T}$ is the turbulent kinetic energy, $P_{K_{T}}$ is the production of turbulent kinetic energy, $R$ is the affect of the breakdown of stream wise fluctuations into turbulence during transition, $R_{N A T}$ is the natural transition production term, $w$ is the dissipation constant, $D_{T}$ is the near wall dissipation, $k_{L}$ is the laminar kinetic energy, $P_{K_{L}}$ is the production of laminar kinetic energy by large scale turbulent fluctuations, $D_{L}$ is near wall dissipation for laminar flow, $D_{\omega}$ is the dissipation, $C_{\omega 1}$ a model constant, $\alpha_{T}$ is the turbulent scalar diffusivity, $f_{W}$ is the wake region damping, and $\alpha_{\omega}$ is the diffusivity.

The airfoil chosen for analysis was provided by the TU Delft University and is a standard DU 97-W-300 blunt trailing edge airfoil. It is shown in FIGURE 6. The DU 97-W-300 has a trailing edge thickness of $1.74 \%$ of the chord length. 


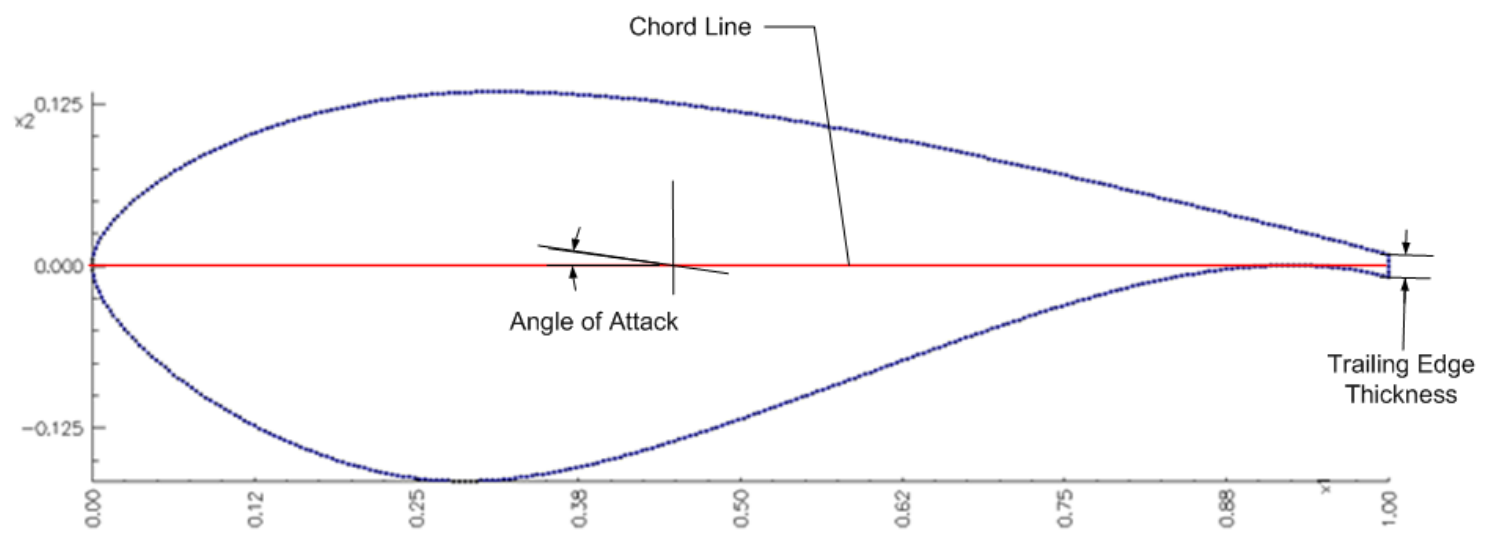

FIGURE 6 - TU Delft DU 97-W-300 blunt trailing edge airfoil

The two equation $k$ - $\omega$ model was used with a specified turbulent kinetic energy and dissipation rate. The turbulent kinetic energy is found from the turbulent intensity and free stream velocity as

$$
k=\frac{3}{2}\left(T_{i} U\right)^{2}
$$

where $T_{i}$ is the turbulent intensity and is set to $0.01 \%$ which corresponds with very little turbulence of the inlet stream, and $U$ is the free stream velocity. The specific dissipation rate of the turbulent flow is approximated as the ratio of turbulent kinetic energy and the turbulent viscosity as 


$$
\frac{k}{\omega} \leq v
$$

where $k$ is the turbulent kinetic energy, $\omega$ the dissipation rate, and $v$ the kinematic viscosity. The Reynolds number chosen for simulation was 3 million so to compare with experimental data. This Reynolds number was achieved through the nondimensionalization of the fluid properties. The airfoil was modeled with a chord length of 1 and the density, velocity, and distance were considered dimensionless 1 as well. This allowed the viscosity of the fluid to be altered such that a high Reynolds number flow could be achieved. The fluid domain around the airfoil was extended 10C in all directions and boundary conditions were specified as shown in FIGURE 7. The farfield is in a square configuration and an inlet velocity is specified in absolute coordinates. An outlet pressure is applied to the right bound of the farfield as zero gauge pressure. The airfoil is specified as a non-slip wall with zero roughness. Given the Reynolds number of 3E6 and $0.01 \%$ turbulent intensity, the turbulent kinetic energy is found from Equation 6 to be $1.5 \mathrm{E}-4 \frac{\mathrm{m}^{2}}{\mathrm{~s}^{2}}$. The specific dissipation is found from Equation 7 to be $500 \mathrm{~s}^{-1}$. These properties are used for both fully turbulent and free transition models. 


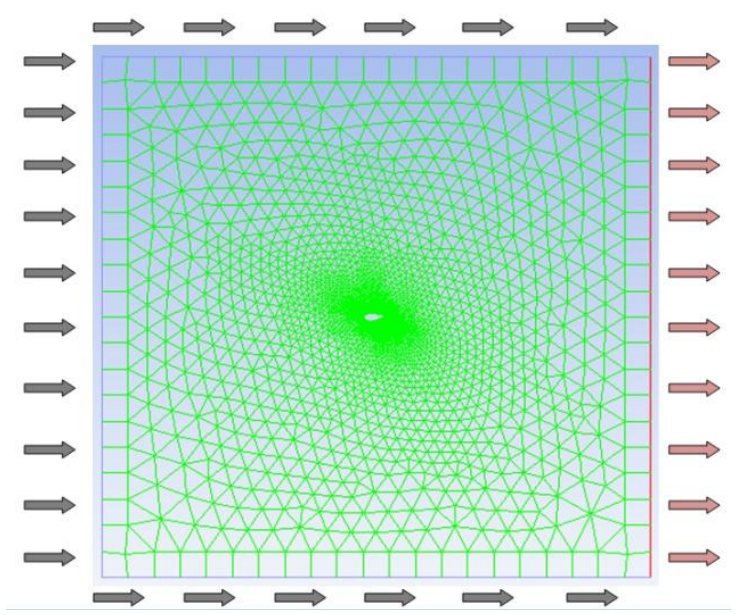

FIGURE 7 - Fluent boundary conditions for fluid simulation

First order upwind discretization schemes were used to initialize the solution after which the solvers were switched to a second order upwind discretization scheme. Airfoil surface force monitors were used to quantify the resultant lift and drag coefficient on the airfoil. These are plotted and monitored during the simulation to determine sufficient convergence of the solution. 


\section{RESULTS AND DISCUSSION}

\section{$\underline{\text { A. A Flat back Airfoil Simulation }}$}

The flat back airfoil was simulated using both an unstructured grid technique and a hybrid grid technique. The unstructured grid is composed of a series of tetrahedral and quadrilateral elements grown to fill the fluid domain. The mesh to discretize the domain is created in a software program accompanying Fluent, ICEM CFD. This software can be used for the creation and analysis of structured and unstructured volume grids. Following import of the airfoil and farfield geometry, meshing parameters are specified and a global mesh scheme is defined, being fully unstructured in this case. A max element size of 1 meter is specified at the farfield boundary and the first cell height normal to the airfoil is determined such that a $\mathrm{y}^{+}$value of 15 is obtained. An inflation layer is grown normal to the airfoil surface at a cell normal growth ratio of 1.1 to a distance of $1 \%$ of the chord length of the airfoil. This near wall layer composes roughly 33 quadrilateral elements normal to the airfoil surface. This meshing is to avoid highly stretched tetrahedral elements with small internal angles which are found to be inadequate to discretize the domain of the boundary layer around an object (Dussin et al 2009). The fully unstructured grid is shown in FIGURE 8 with a detail view of the grid surrounding the 
airfoil presented in FIGURE 9. Of note is the transition from quadrilateral inflation layer to unstructured tetrahedral mesh at the trailing edge of the airfoil. This transition was implemented because it is difficult to map a convex corner with the quadrilateral elements. Precise geometry can be discretized using tetrahedral elements while the boundary layer is defined using quadrilateral elements. This mesh has circumferential spacing of 0.0004 meter corresponding to over 5000 cells circumferentially around the airfoil. The mesh example of FIGURE 8 is composed of over 300,000 elements.

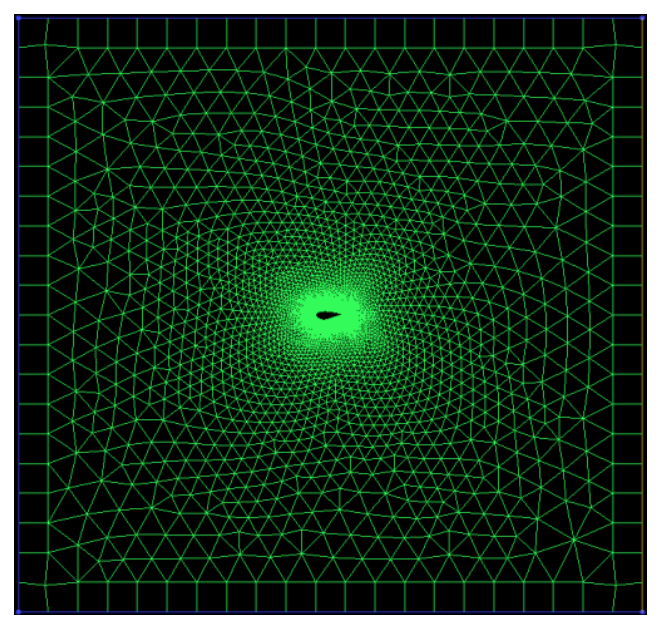

FIGURE 8 - Fully unstructured fluid domain mesh

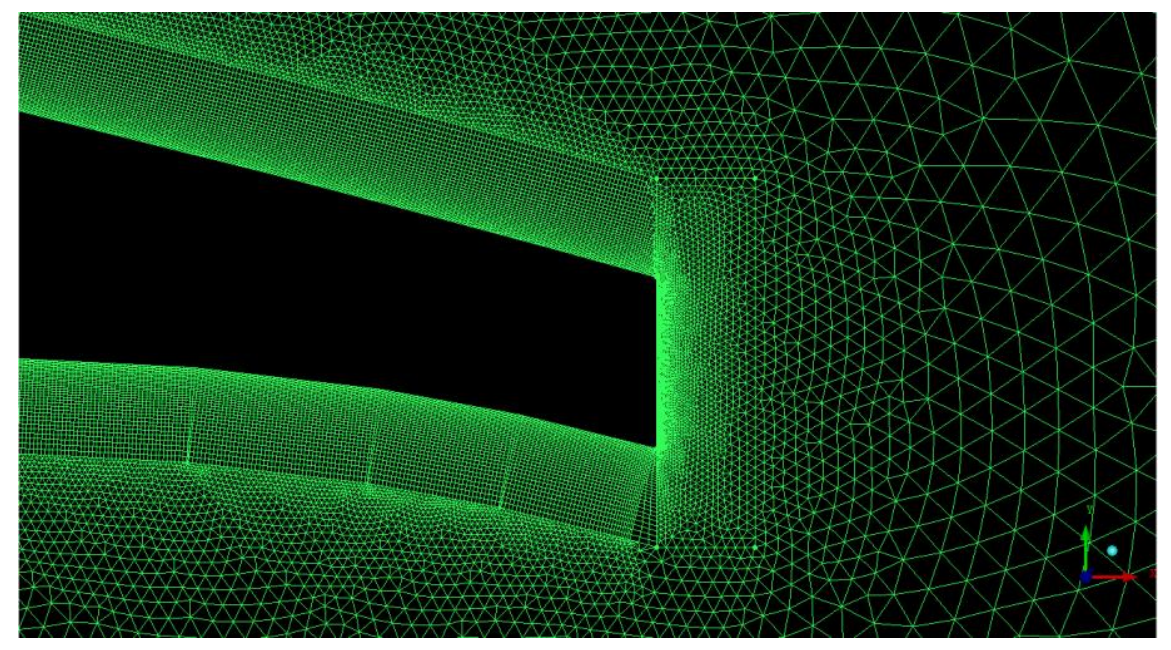

FIGURE 9 - Detail view of fully unstructured airfoil mesh 
The hybrid grid technique is one in which a structured quadrilateral grid is created circumferentially around the airfoil after which a series of tetrahedral unstructured cells are grown from near wall regions to the farfield. Further into the free stream portion of the flow the tetrahedral elements are used to efficiently discretize the domain without the density and stretching that would be required with quadrilateral elements. The structured o-grid immediately around the airfoil is constructed with a first cell spacing identical to that of the fully unstructured grid resulting in a $y^{+}$value of 15 . This grid was composed of 50 radial lines from the airfoil with a normal spacing growth ratio of 1.2. A considerably smaller number of axial lines was used at only 250 . Further refinements will be conducted to determine the most appropriate radial and axial element density. Following construction of the structured elements immediately surrounding the airfoil, an unstructured grid was grown to the farfield boundary 10c distance in all directions. The use of a hybrid grid allows the numerical accuracy and efficiency of the structured grid within the boundary layer and the flexibility of an unstructured grid in the far field. A zoom picture of this grid displaying the structured and unstructured elements is shown in FIGURE 10. The convex corners defining the trailing edge of the airfoil were a challenge to mesh properly with the structured elements. 


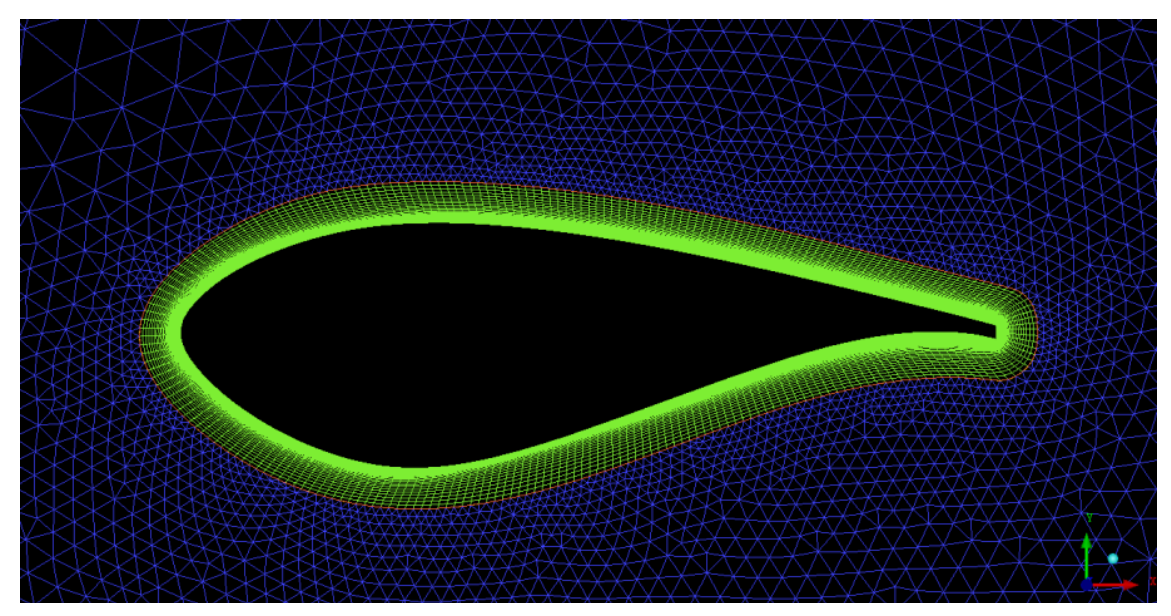

FIGURE 10 - Hybrid grid discretizing fluid domain

A sensitivity analysis was conducted on the airfoil boundary layer cell density and its effect is gauged via force monitor history. Both grids are simulated and lift coefficient is calculated to be compared to data measured experimentally by the Delft Technical University.

Scaling the cell spacing of the fully unstructured mesh in the circumferential direction of the airfoil inflation layer had the effect of reducing the total number of elements by roughly the same scale factor. The circumferential spacing was increased from 0.0004 to 0.004 which results in roughly 500 quadrilateral elements composing the first cell height around the airfoil. Correspondingly the total element count is reduced to just under 40,000 or roughly an order of magnitude less than shown in FIGURE 8. This grid is shown in FIGURE 11. A further reduction in grid points around the airfoil led to a mesh which defined the circumferential spacing around the airfoil in only 300 elements. Further a grid with 150 elements around the airfoil was created to judge the absolute minimum number of required cells to sufficiently capture flow around the airfoil. The 
first cell height, growth ratio, and cell density in the radial direction were maintained constant in the preceding analyses.

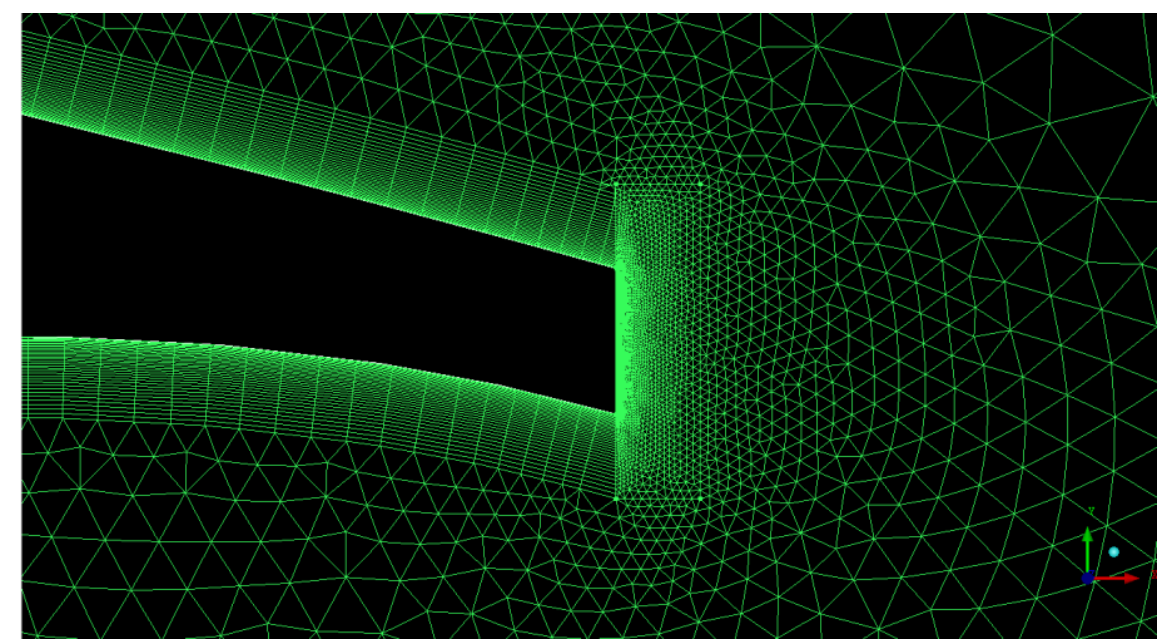

FIGURE 11 - Structured grid circumferential spacing sensitivity mesh

These grids were tested using the two equation $k-\omega$ model at angle of attack 2.04 degrees. The coefficients of lift for the airfoils of these simulations are presented in TABLE I below. The highest density mesh reported the highest value of lift and also the closest to experimental data provided by The Delft Technical University. However, the data suggests that a circumferential grid spacing of 300 is adequate to capture flow behavior while maintaining a reasonable cell count.

\section{TABLE I}

UNSTRUCTURED GRID SENSITIVITY ANALYSIS LIFT VALUES, 2.04 AOA

\begin{tabular}{|c|c|c|c|c|c|}
\hline$\underline{\text { Airfoil Grid }}$ & $5000 \times 33$ & $500 \times 33$ & $\mathbf{3 0 0 \times 3 3}$ & $150 \times 33$ & Delft \\
\hline$\underline{\mathrm{C}}_{\mathrm{l}}$ & 0.525 & 0.496 & $\mathbf{0 . 5 0 4}$ & 0.444 & $\mathbf{0 . 5 4 9}$ \\
\hline
\end{tabular}


For the hybrid grid the circumferential grid density was initially set to 250 based on the results obtained from TABLE I. This count was then increased to 350 and finally 450 around the airfoil. These grids were simulated identically to the unstructured grids with the exception of an increased angle of attack and force history was recorded. The angle of attack was increased to 6.18 degrees. TABLE II lists the airfoil grid variation and corresponding recorded coefficient of lift. Of note is the good agreement of numerical simulation to experimental data. Lift begins to drop as circumferential line density is increased. However, the difference between the finest grid (450x50) and the coarsest grid (250x50) is less than $1 \%$.

TABLE II

HYBRID GRID CIRCUMFERENTIAL DENSITY SENSITIVITY ANALYSIS LIFT VALUES, 6.18 AOA

\begin{tabular}{|c|c|c|c|c|}
\hline$\underline{\text { Airfoil Grid }}$ & $\mathbf{2 5 0 \times 5 0}$ & $350 \times 50$ & $450 \times 50$ & Delft \\
\hline$\underline{C}_{1}$ & $\mathbf{0 . 9 7 3}$ & 0.974 & 0.968 & $\mathbf{1 . 0 5 2}$ \\
\hline
\end{tabular}

A radial line density sensitivity analysis is then performed on the structured grid immediately surrounding the airfoil in the hybrid mesh. The initial grid, taken from the previous test to be $250 \times 50$ elements, is first coarsened and then refined to determine effect radial element density has upon the force monitor history. These simulations were conducted using the two equation $k$ - $\omega$ model at a 6.18 degree angle of attack at Reynolds number of 3 million. Coefficient of lift data is presented in TABLE III below. 
TABLE III

HYBRID GRID RADIAL DENSITY SENSITIVITY ANALYSIS LIFT VALUES

\begin{tabular}{|c|c|c|c|c|}
\hline$\underline{\text { Airfoil Grid }}$ & $250 \times 35$ & $\mathbf{2 5 0 \times 5 0}$ & $250 \times 65$ & Delft \\
\hline$\underline{\mathrm{C}}_{\mathrm{l}}$ & 0.973 & $\mathbf{0 . 9 7 3}$ & 0.975 & $\mathbf{1 . 0 5 2}$ \\
\hline
\end{tabular}

TABLE III suggests that the radial line density variation has little effect on the outcome of the numerical solution. The medium density grid (250x50) therefore is chosen for further fluid simulation.

Sensitivity analyses conducted at a single angle of attack provide minimal conclusions on the performance of the flat back airfoil which could see a wide variety of angles of attack while in service on the wind turbine. Performance through a sweep of angles was needed to determine the behavior of the airfoils at low angles as well as high angles of attack characterized by vortex shedding. Using the two equation $k-\omega$ model, simulations were performed using both the unstructured mesh and hybrid mesh at varying angles of attack from 2 to 10 degrees at Reynolds number of 3 million. Force monitor history was used to determine the coefficient of lift and coefficient of drag of the airfoil. A lift plot is shown in FIGURE 12 which compares experimental lift coefficient values provided by Delft University of Technology with numerical results. Coefficient of drag values are recorded in TABLE IV. There was an average difference of $-8.8 \%$ between experimental and numerical lift when using a hybrid mesh. A $-14.1 \%$ average difference in lift was recorded when comparing experimental with numerical results using a fully unstructured mesh. Coefficient of drag was more poorly predicted with an average over prediction of $100 \%$ when compared to experimental data. Stone et al (2009) draws 
similar conclusions about the over predictions of lift in two dimensional simulations.

There was, though, good agreement between the different mesh schemes.

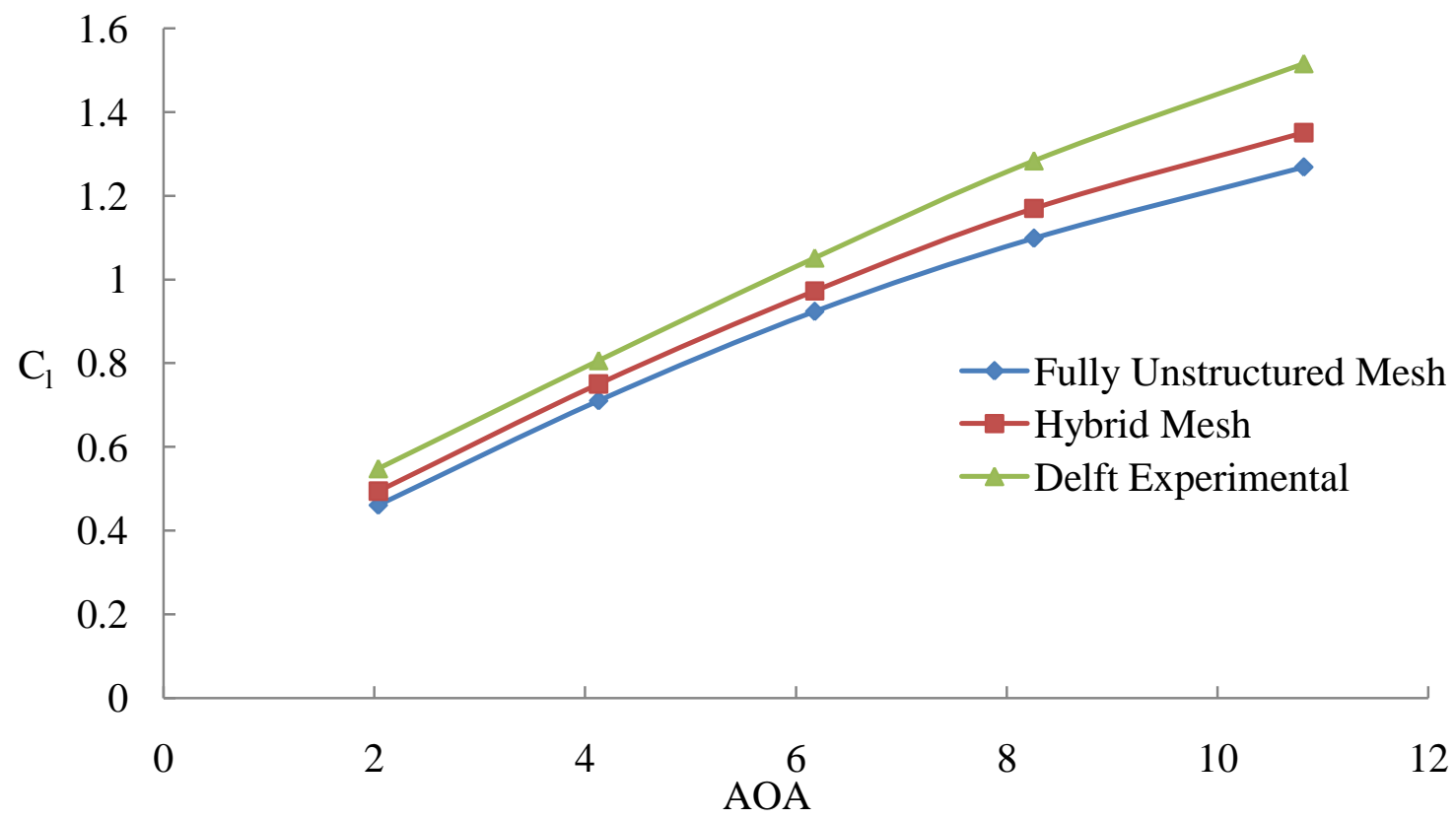

FIGURE 12 - Coefficient of lift versus angle of attack two equation model

TABLE IV

COEFFICIENT OF DRAG VALUES AT VARYING AOA USING TWO EQUATION MODEL

\begin{tabular}{|c|c|c|c|c|c|}
\hline Test & $\underline{2.04}$ & $\underline{4.13}$ & $\underline{6.18}$ & $\underline{8.26}$ & $\underline{10.82}$ \\
\hline $\begin{array}{c}\text { Unstructured } \\
\text { Mesh }\end{array}$ & 0.02 & 0.021 & 0.024 & 0.028 & 0.036 \\
\hline Hybrid Mesh & 0.02 & 0.021 & 0.025 & 0.029 & 0.036 \\
\hline $\begin{array}{c}\text { Delft } \\
\text { Experimental }\end{array}$ & 0.01 & 0.011 & 0.012 & 0.013 & 0.016 \\
\hline
\end{tabular}

Analysis was performed again for the unstructured and hybrid meshes using the three equation $k$ - $\omega$ transition model for comparison with experimental values reported in FIGURE 12 and TABLE IV. This scheme predicts the location of the transition from 
laminar to turbulent flow in the flow field. A chart comparing angle of attack to coefficient of lift for both unstructured and hybrid mesh schemes using fully turbulent and transition models is shown in FIGURE 13. It is clear that higher lift is predicted by the transition equation using both the unstructured and hybrid grids. The hybrid grid simulated with the transition model actually over predicts lift generation reported by experimental results at low angles of attack but falls below experimental data above 6 degrees AOA. Coefficient of drag data is presented for all cases thus far in TABLE V. It is clear that the transition model improves the prediction of drag coefficient.

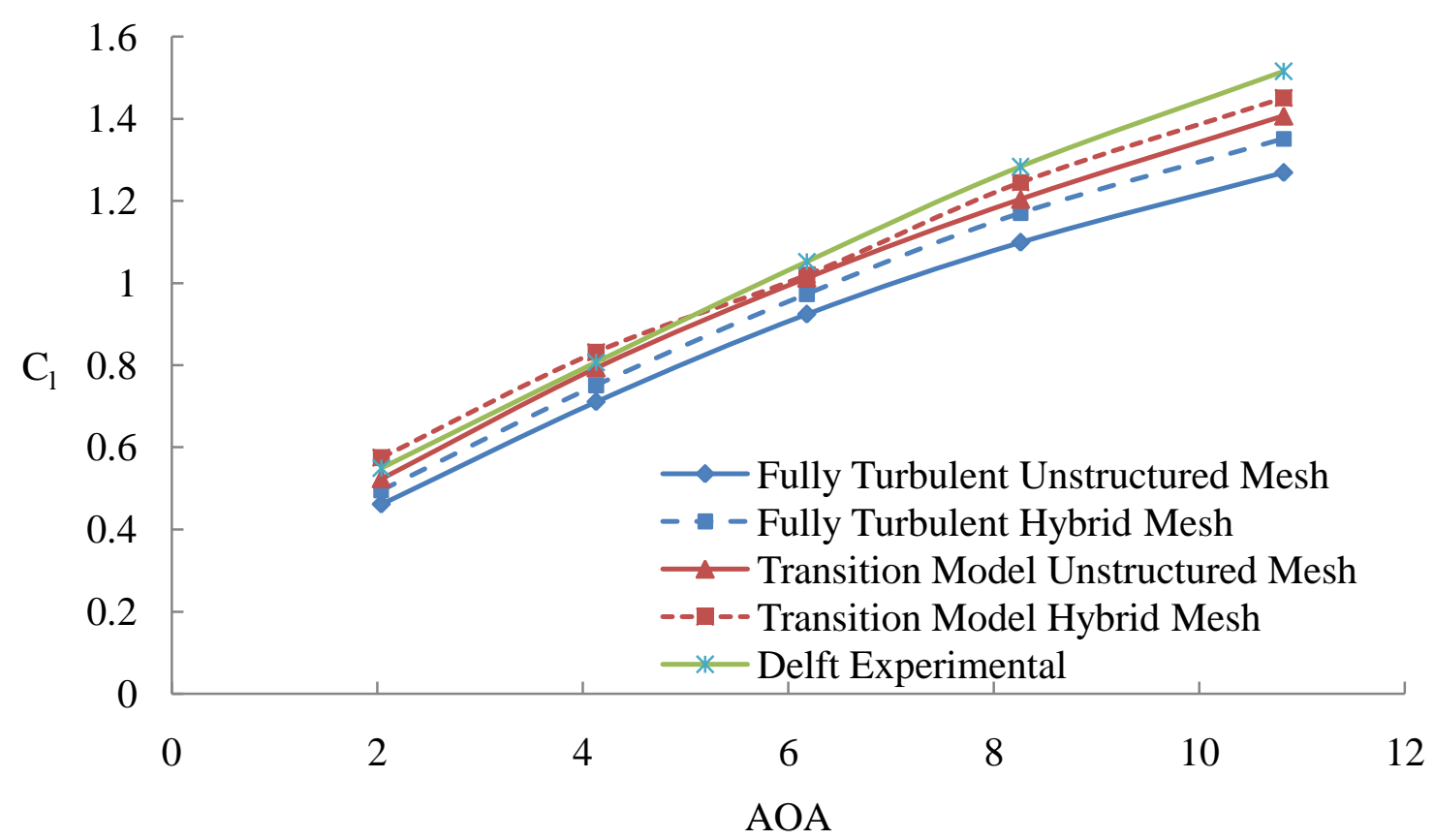

FIGURE 13 - Two and three equation k- $\omega$ model lift coefficient comparison 
TABLE V

COEFFICIENT OF DRAG USING TWO EQUATION AND THREE EQUATION K- $\Omega$ MODEL

\begin{tabular}{|c|c|c|c|c|c|}
\hline Test & $\underline{\mathbf{2 . 0 4}}$ & $\underline{\mathbf{4 . 1 3}}$ & $\underline{\mathbf{6 . 1 8}}$ & $\underline{\mathbf{8 . 2 6}}$ & $\underline{\mathbf{1 0 . 8 2}}$ \\
\hline $\begin{array}{c}\text { Fully Turbulent } \\
\text { Unstructured Mesh }\end{array}$ & 0.02 & 0.021 & 0.024 & 0.028 & 0.036 \\
\hline $\begin{array}{c}\text { Fully Turbulent } \\
\text { Hybrid Mesh }\end{array}$ & 0.02 & 0.021 & 0.025 & 0.029 & 0.036 \\
\hline $\begin{array}{c}\text { Transition Model } \\
\text { Unstructured Mesh }\end{array}$ & 0.018 & 0.019 & 0.023 & 0.026 & 0.034 \\
\hline $\begin{array}{c}\text { Transition Model } \\
\text { Hybrid Mesh }\end{array}$ & 0.015 & 0.018 & 0.023 & 0.026 & 0.033 \\
\hline Delft Experimental & 0.01 & 0.011 & 0.012 & 0.013 & 0.016 \\
\hline
\end{tabular}

Flow field visualization is a secondary tool to characterize the meshing and solving scheme wherein vortex shedding and flow separation can be quantified. Vorticity contours allow the relative curl, or rotation, of the fluid to be quantified and displayed. Plots of both unstructured and hybrid mesh schemes using the two equation and three equation turbulence models are shown in FIGURE 14. The vorticity contours from different grids and turbulence models appear nearly identical. 


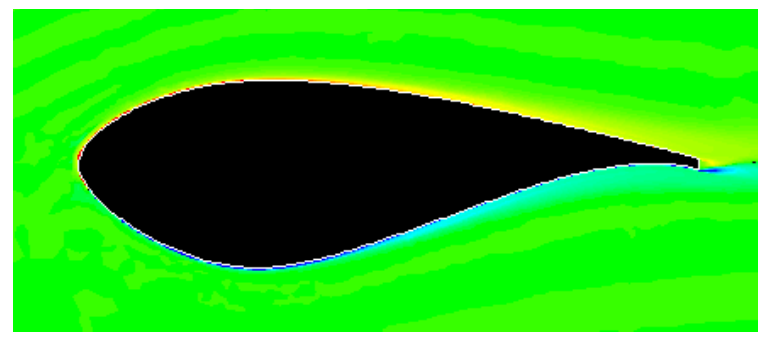

a.

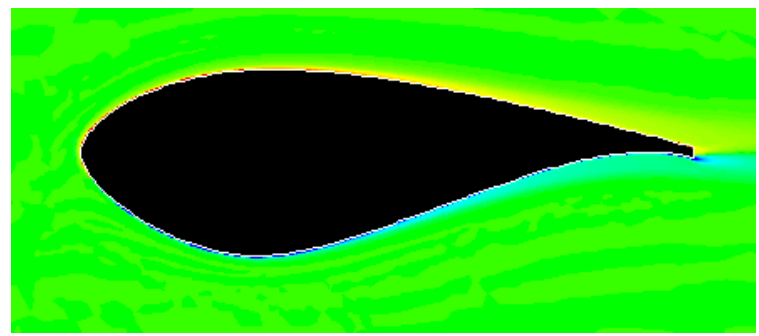

c.

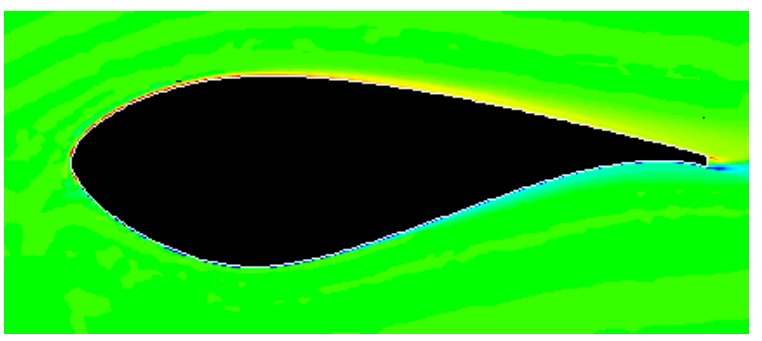

b.

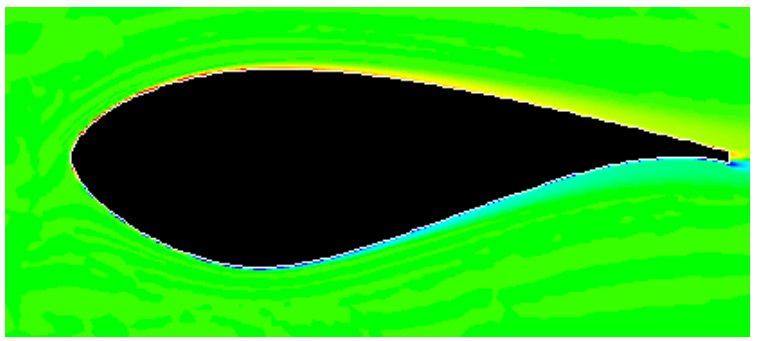

d.

FIGURE 14 - Vorticity contours, a. Unstructured grid/turbulent scheme, b. Unstructured grid/transition scheme, c. Hybrid grid/turbulent scheme, d. Hybrid grid/transition scheme, $6.18 \mathrm{AOA}$

Surface pressure distribution is also a useful tool to validate numerical techniques against experimental results. As the lift coefficient is obtained from integration of the pressure along the airfoil surface, the plot of pressure distribution could be an even more proper judge of airfoil performance than that of lift generated alone. A severely skewed pressure contour that returns a comparable lift coefficient to that of experimental methods suggests an improper numerical scheme. Delft Technical University, along with providing coefficient of lift values for the airfoil, has also provided pressure coefficient data along the airfoil surface. This data can be compared to numerical data obtained in the above mentioned simulations. FIGURE 15 plots the coefficient of pressure for both hybrid and unstructured grids using a transition turbulence model against experimental data. The comparison indicates that both grids approximate the leading and trailing edge pressure profiles with only slight deviation in the prediction of the suction surface of the airfoil by both meshes. Both grids slightly under predict the minimum pressure values on 
the suction surface. The hybrid grid produces a smooth pressure distribution along the upper airfoil surface similar to the experimental results while the unstructured grid generates pressure irregularities.

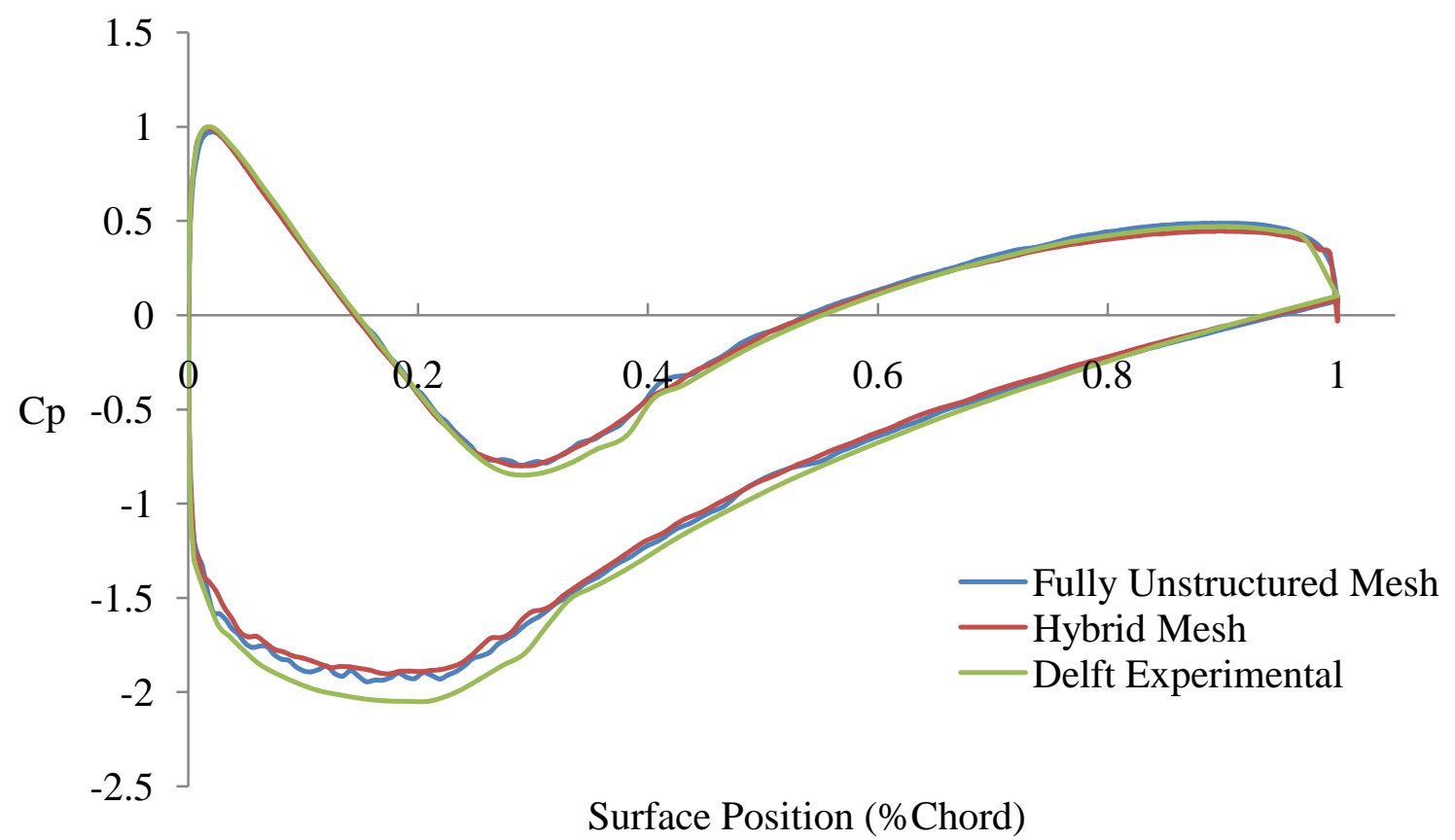

FIGURE 15 - Airfoil surface coefficient of pressure values numerical vs. experimental, three equation model, 6.18 AOA 


\section{B. Study of Trailing Edge Thickness}

The figures and data presented in the aforementioned flat back airfoil simulation section lead to the conclusion that both fully unstructured and hybrid meshing schemes are in close agreement with each other and experimental lift and pressure distribution. Additionally both the two equation $k$ - $\omega$ model and three equation $k$ - $\omega$ free transition models are in good agreement with experimental results. The free transition model, as indicated by FIGURE 13 and FIGURE 15, has a slight advantage in the prediction of lift coefficient and pressure coefficient at the expense of computation time in solving a third transport equation. Additionally the transition model gives better prediction of drag coefficient.

To apply these findings to the investigation of thick trailing edge airfoils the geometry must be modified to increase trailing edge width. In accordance with research carried out by the wind power groups of Sandia National Laboratories and Georgia Polytechnic Institute and State University, a trailing edge thickness of $10 \%$ of the chord length of the airfoil was chosen for numerical simulation. This airfoil was created as shown in FIGURE 4 by equally adding thickness to the trailing edge above and below the camber line of the airfoil. Unstructured meshing is utilized for this airfoil due to its convex corners and cell skew associated with structured/unstructured hybrid meshing. The unstructured mesh is created identically to that of the thin $1.74 \%$ chord length thickness airfoil of FIGURE 11 with 300 by 33 quadrilateral circumferential elements immediately around the airfoil and tetrahedral elements grown from the near wall layer to the farfield boundaries. This mesh is shown in FIGURE 16. This grid was simulated 
using both the fully turbulent and the free transition $k-\omega$ models at Reynolds number of 3 million and angles of attack varying from two to ten degrees. Coefficient of lift and drag data is collected. A comparison to simulation results obtained with an airfoil with trailing edge thickness equal to $1.74 \%$ of chord length is shown for coefficient of lift in FIGURE 17.

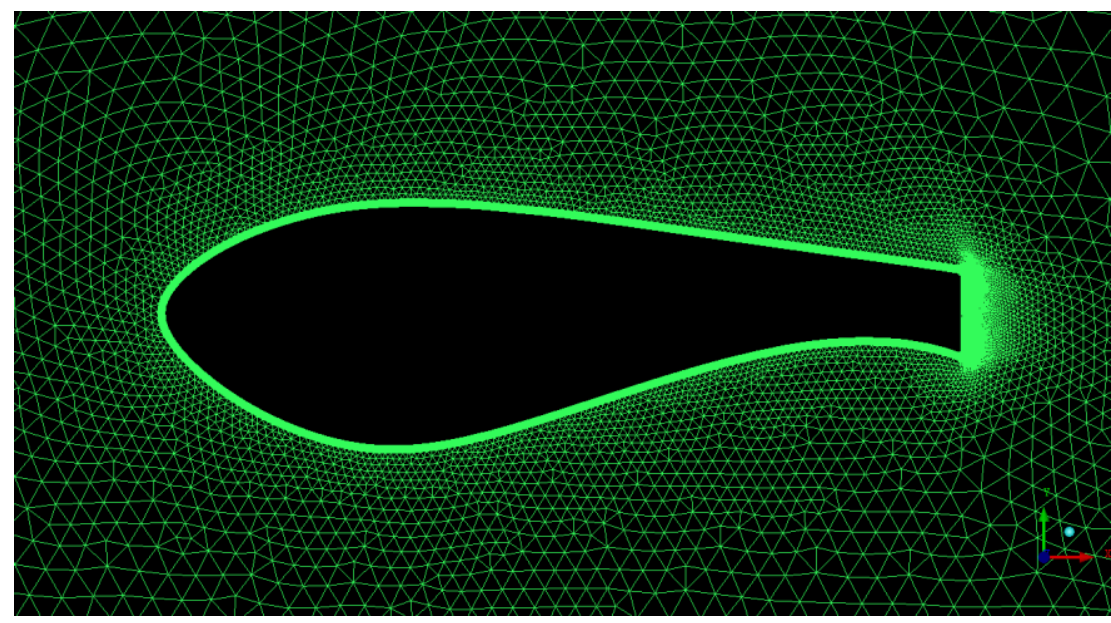

FIGURE 16 - Unstructured mesh for airfoil trailing edge width $10 \%$ of chord

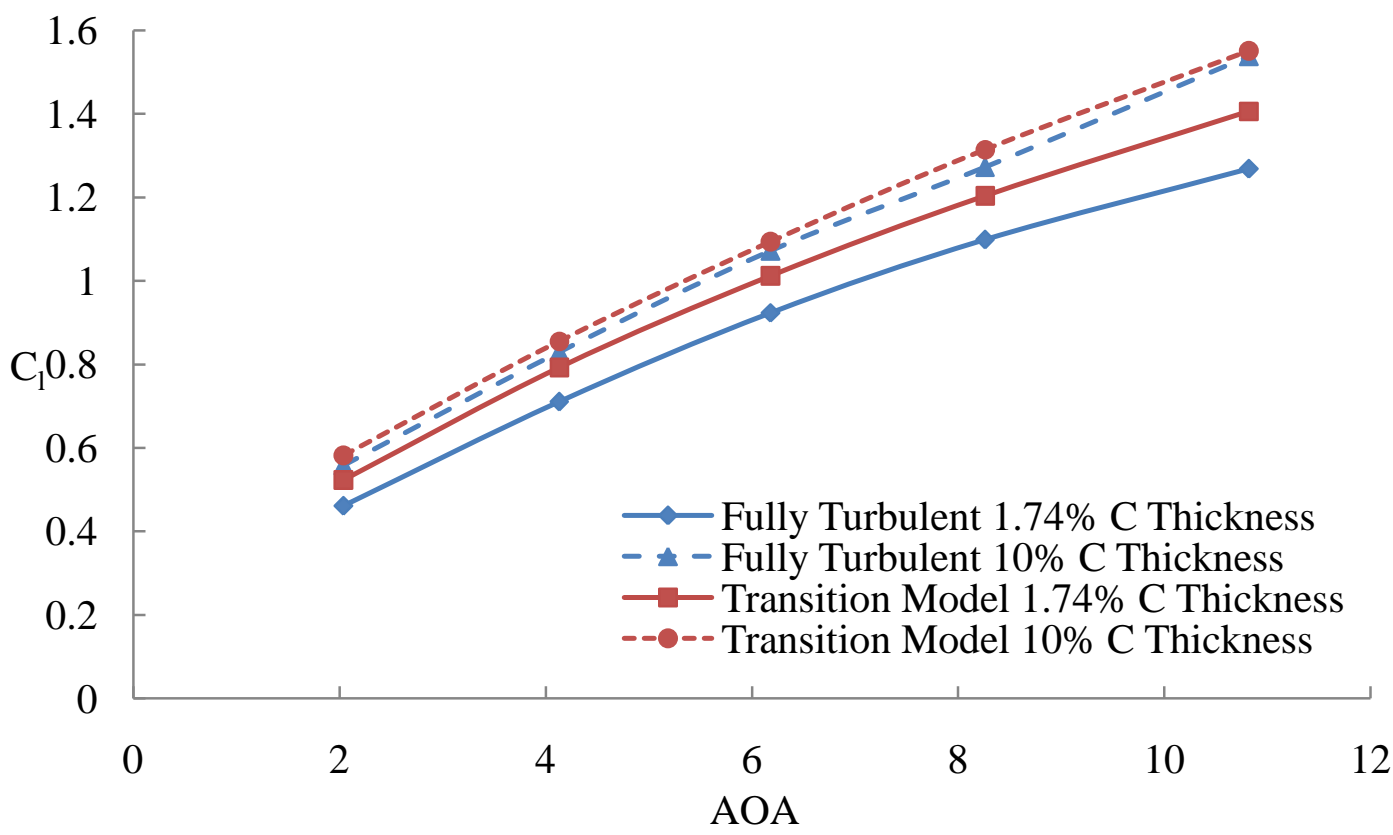

FIGURE 17 - Airfoil trailing edge thickness lift coefficient comparison 
Lift production is higher for the thicker trailing edge airfoil as expected from literature (van Dam et al 2008). The average increase in lift using the two equation turbulence model was $18 \%$ while the three equation transition model predicts an average $10 \%$ increase in lift at all angles of attack. The cost of this increased lift is an increase in drag on the airfoil. An increase in drag is seen due to the increased tendency for the airfoil to experience unsteady flow separation and vortex shedding at the blunt trailing edge. A lift to drag polar plot will characterize the increased drag production when compared to the thinner $1.74 \%$ chord length trailing edge thickness airfoil. This plot is shown in FIGURE 18. The three equation turbulent free transition model reports average lower drag values than does the two equation fully turbulent solver scheme. Both schemes report an average double the amount of drag with the thicker trailing edge airfoil.

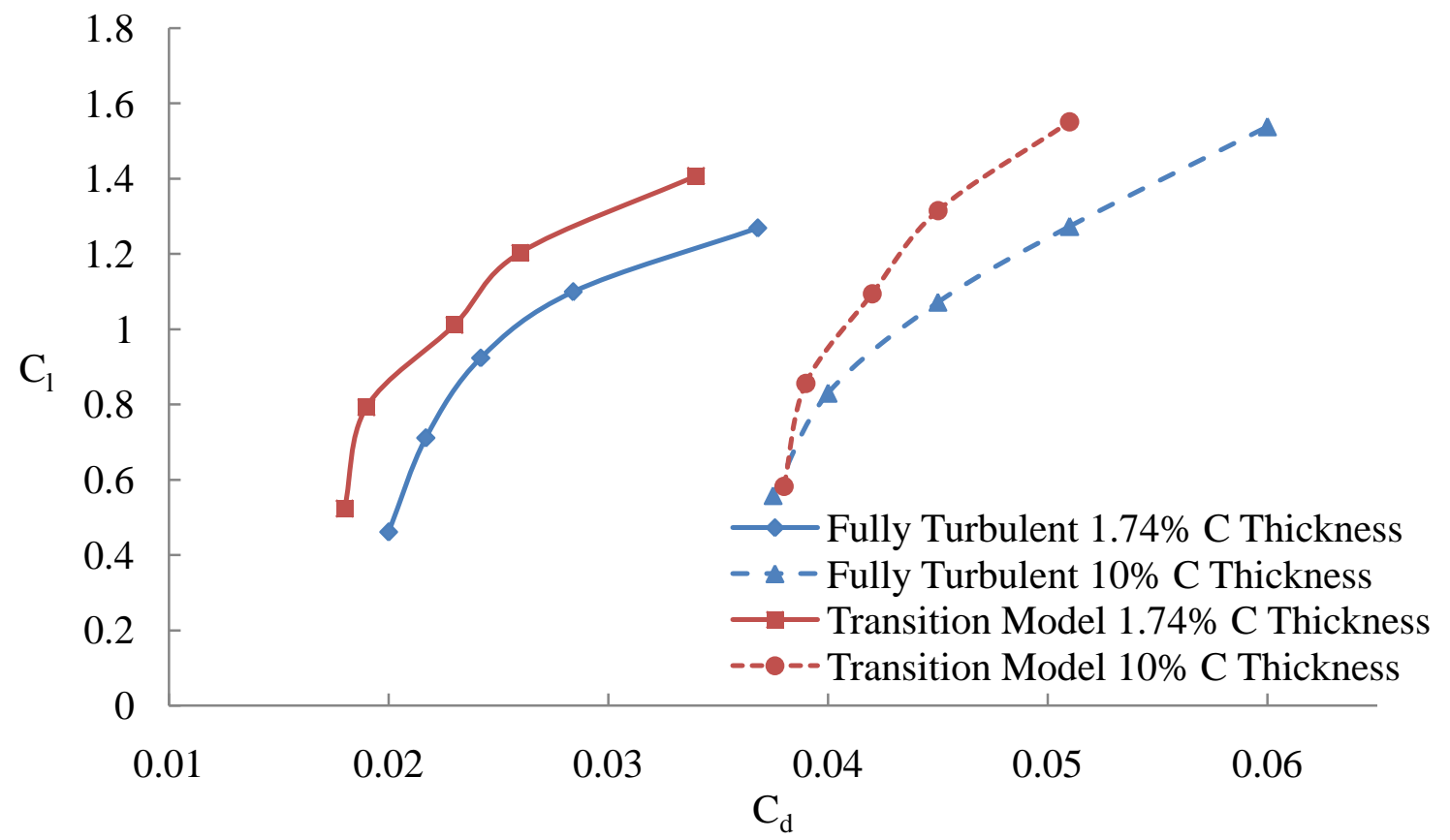

FIGURE 18 - Lift-drag polar plot for 1.74\% C and 10\% C trailing edge thickness, 2-10 degree AOA 
Flow field characterization suggests that the increased drag is due to the periodic vortex shedding from the blunt trailing edge. A low pressure regime develops directly aft of the trailing edge and induces flow separation and vortex structure formation. FIGURE 19 displays the signed vorticity contour plot. It is seen that vortices with opposite rotations are alternately shed from the upper and lower surface of the airfoil at the trailing edge in a periodic fashion. To illustrate this lower pressure that develops at the trailing edge of the thicker flat back airfoil a plot of surface pressure coefficient is shown and compared to results for the $1.74 \%$ chord thickness airfoil in FIGURE 20. It is seen that the pressure distribution over the first half of the thicker airfoil is nearly identical to the pressure of the thinner airfoil. This is to be expected as thickness was added only to the trailing edge and the aft half of the airfoil. The lower surface of the thicker trailing edge airfoil sees an increased pressure from the fluid flow while the upper surface along the last $1 / 4$ chord experiences a lower surface pressure. This accounts for the increased lift generation by the thicker blunt trailing edge airfoil. Increased drag is created due to the magnitude difference in upper and lower surface pressures at the trailing edge. The $10 \%$ chord trailing edge thickness airfoil has an average 33\% higher pressure gradient at the trailing edge than does the $1.74 \%$ chord trailing edge thickness airfoil. This makes for an unfavorable pressure gradient which can lead to premature flow separation (van Dam et al 2008). 


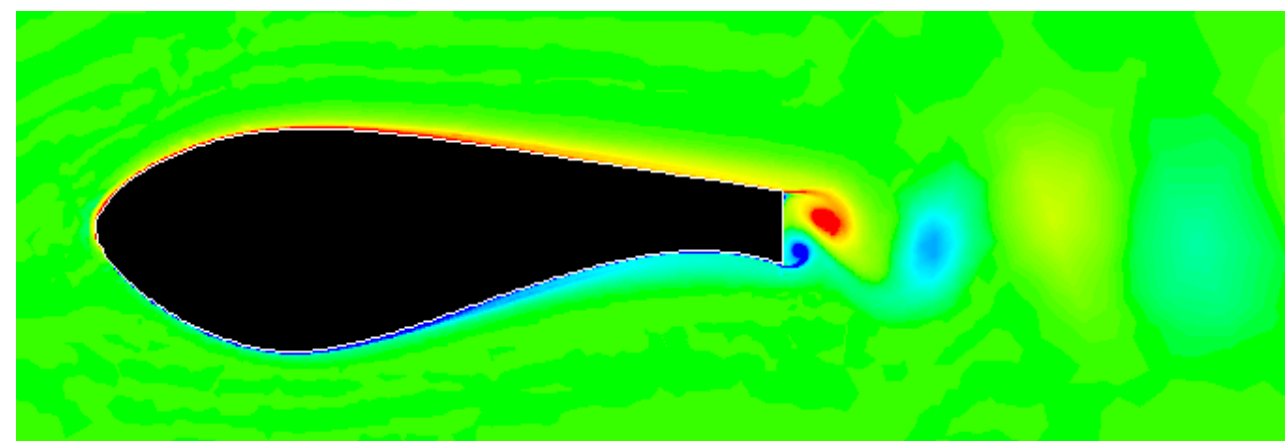

FIGURE 19 - Instantaneous vorticity contours for 10\% C trailing edge thickness airfoil, 6.18 AOA

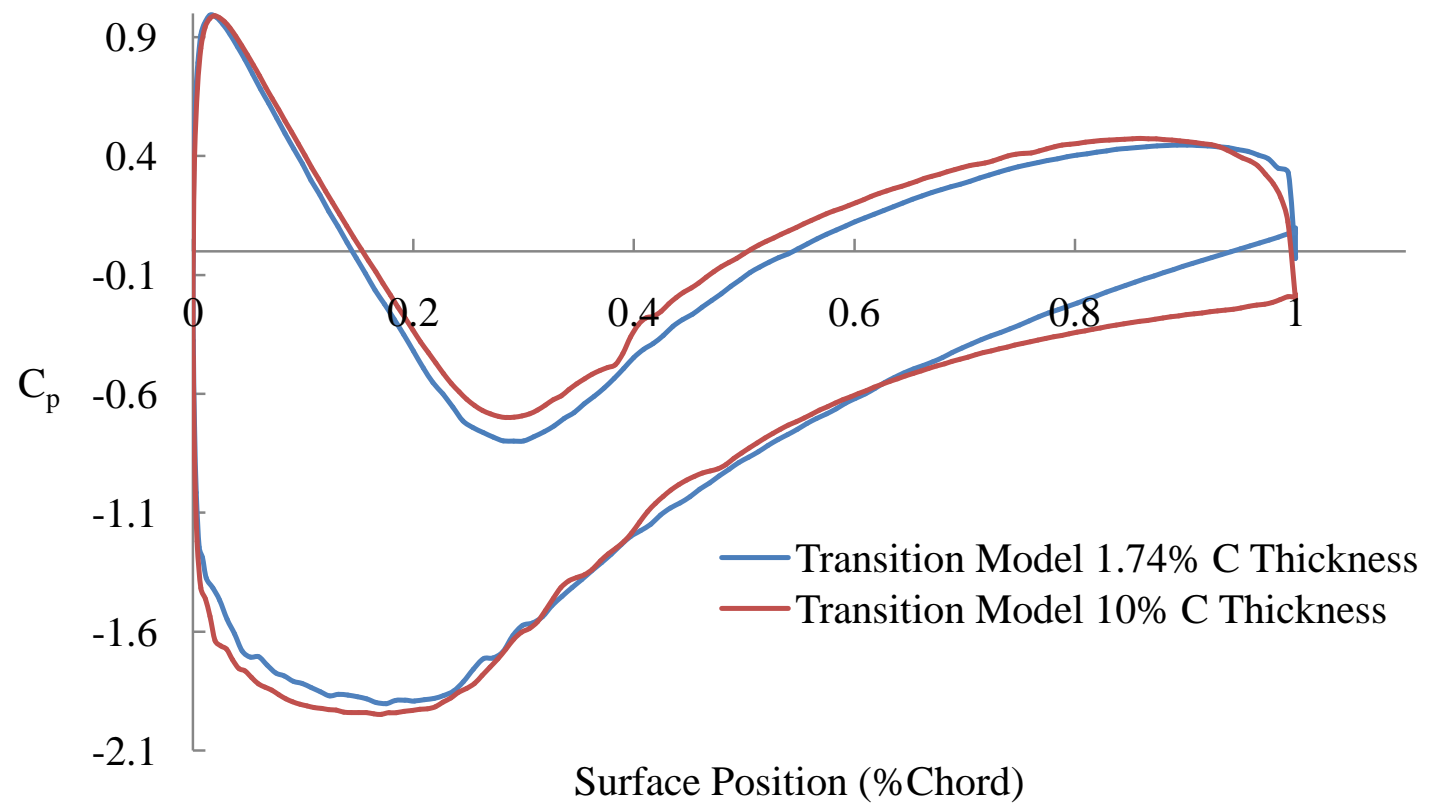

FIGURE 20 - Airfoil surface coefficient of pressure values $1.74 \% \mathrm{C}$ vs. $10 \% \mathrm{C}$ trailing edge thickness, 6.18 AOA 


\section{Study of Trailing Edge Modifications}

According to van Dam et al (2008) one of the most common methods used to combat trailing edge pressure decrease and thus vorticity shedding is the addition of a splitter plate. This plate will be attached along the camber line of the airfoil to the trailing edge and have an optimum length equal to the width of the trailing edge of the airfoil. The addition of the splitter plate is intended to offset the periodic vortices further downstream from the airfoil thereby decreasing upper and lower surface pressure gradients and resulting drag. The splitter plate length was further investigated to determine the effect a longer or shorter treatment has upon airfoil performance.

To test the aerodynamic performance dependence upon trailing edge splitter plate length, the treatment was varied in chord wise length from $2 \%$ to $10 \%$. All airfoils were meshed using the unstructured method as shown in FIGURE 16 with a consistent $300 \mathrm{x}$ 33 quadrilateral circumferential elements immediately around the airfoil pressure and suction surfaces. The number of grid points was varied for the differing splitter plate lengths but a size corresponding to a $\mathrm{y}^{+}$value of 15 was maintained at the geometry surface. The discretized domains corresponding to the airfoil with a splitter length of $2 \%$ chord and the airfoil with splitter length of $10 \%$ chord are shown in FIGURE 21. These grids contain roughly 26000 and 34000 elements respectively with the difference due to the increased density near the trailing edge due to splitter length. 


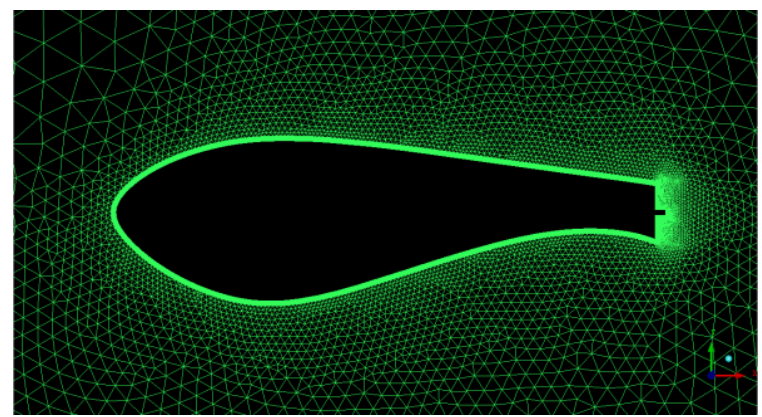

a.

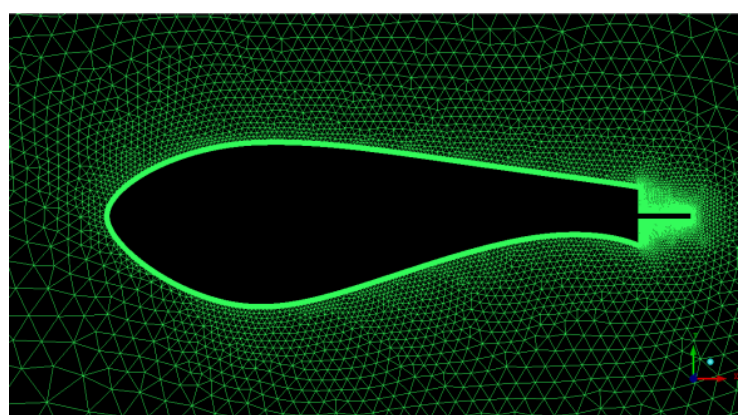

b.

FIGURE 21 - Unstructured grids, a. Flat back airfoil with $2 \%$ chord wise splitter plate length, b. Flat back airfoil with $10 \%$ chord wise splitter plate length

Four grids, with splitter plate chord-wise lengths of 2, 5, 7.5, and 10\%, were simulated using both the turbulent two-equation and the turbulent transition threeequation $k$ - $\omega$ models at Reynolds number of 3 million and angles of attack varying from two to ten degrees. FIGURE 22 presents the lift-drag polar plot of all four splitter plate lengths versus the flat back airfoil with no trailing edge treatment. The polar plot was used as there is a negligible change in lift generation regardless of the trailing edge treatment therefore a lift plot versus angle of attack would be relatively uninformative. It should be further emphasized that lift production by the flat back airfoil with trailing edge treatments is comparable to the flat back airfoil without trailing edge treatment. The splitter plate's lengths are included in the coefficient of lift calculation.

Drag is reduced by adding the splitter plate to the trailing edge (FIGURE 22). The small $2 \%$ chord wise splitter plate reduced drag an average of $9 \%$ while the $7.5 \%$ chord wise splitter reduced it again $14.5 \%$. The most substantial reductions in drag were seen with the $5 \%$ and $10 \%$ chord wise length splitter plates. These two configurations saw an average of $18 \%$ and $21 \%$ reduction in drag respectively from the airfoil with no trailing edge treatment. This supports the claims of van Dam et al (2008). At higher angles of 
attack the more compact 5\% chord wise length splitter plate shows slightly increased performance over the $10 \%$ chord wise length splitter.

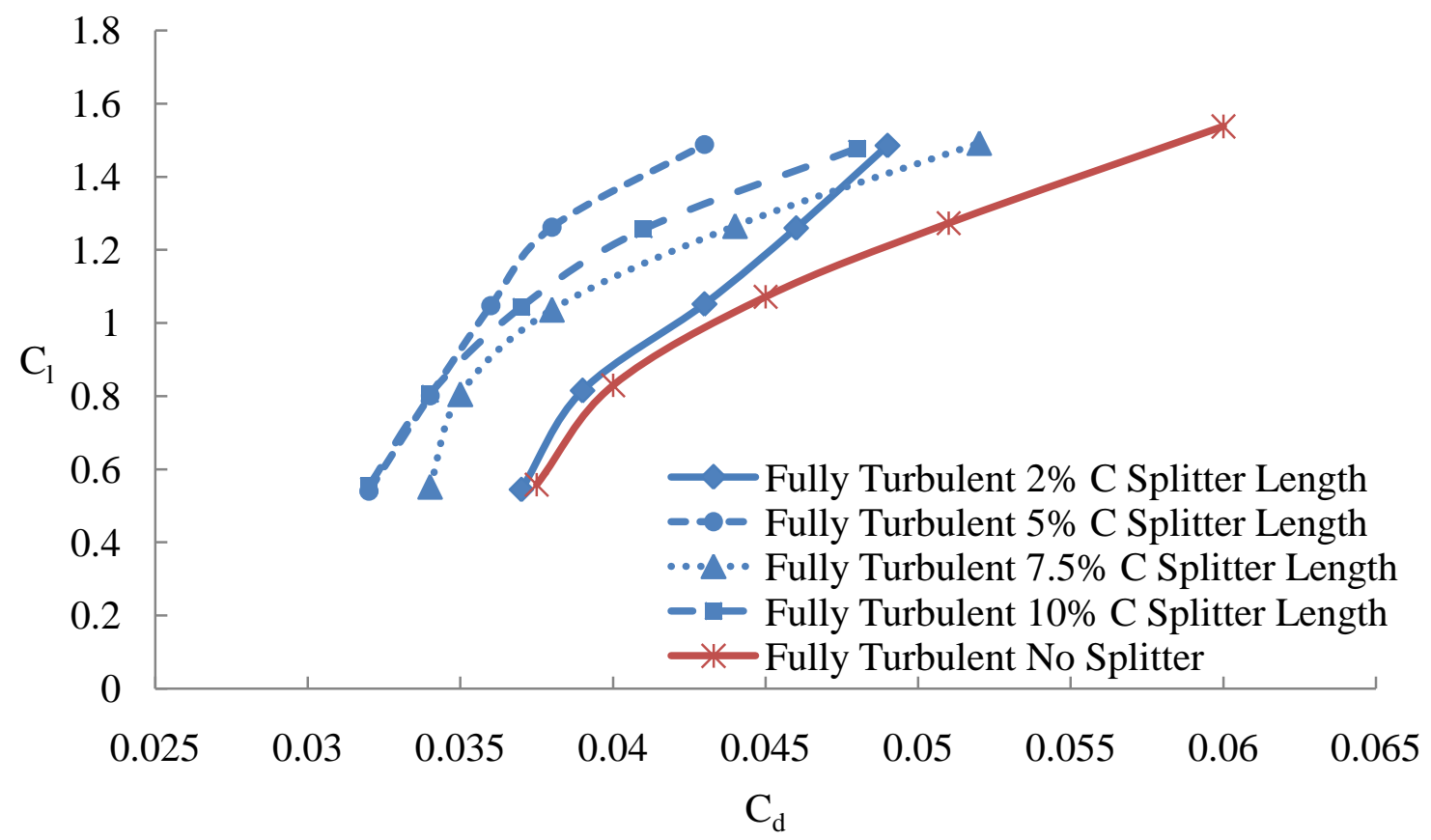

FIGURE 22 - Lift-drag polar plot for varying splitter length from 2-10 degree AOA, fully turbulent scheme

Similar tests were run using the three equation $k$ - $\omega$ model and the polar plots of the resulting lift and drag monitors are plotted in FIGURE 23. Conversely to the data shown in FIGURE 22 there appears to be no benefit to performance by adding either the $2 \%$ or 7.5\% splitter plate to the flat back airfoil using the turbulent transition prediction model. In fact there is slightly more drag predicted at higher angles of attack for these two configurations in comparison to an unmodified airfoil. However both the 5\% and 10\% splitter plate additions showed slight decreases in overall drag of $2.5 \%$ and $5 \%$ respectively. Overall, using the three equation $k-\omega$ model results in lower predictions in the reduction of drag coefficient for the flat back airfoils with trailing edge treatments. 


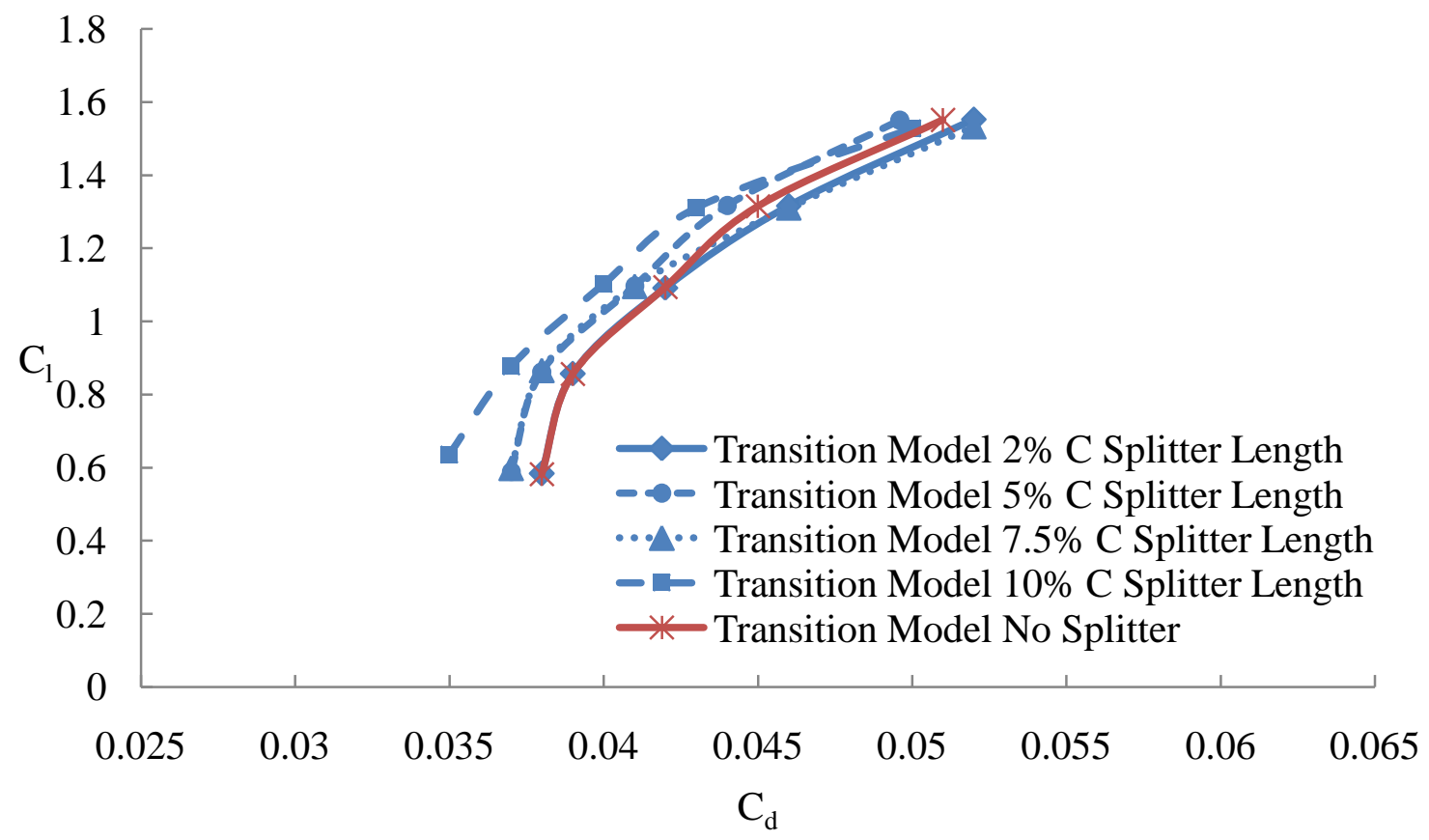

FIGURE 23 - Lift-drag polar plot for varying splitter length from 2-10 degree AOA, free transition scheme

Study of the flow fields can provide insights as to the decrease in base drag predicted by both turbulent and transition models. FIGURE 24 displays signed vorticity contours for the flat back airfoil with varying lengths of splitter plate using the fully turbulent solver and at an angle of attack of 6.18 degrees. As van Dam et al (2008) predicted the addition of the splitter plate to the flat back airfoil serves to offset the vortex street away from the airfoil and decrease the drag associated from periodic vortex shedding. The vortex street phenomenon appears to be reduced correspondingly with a longer splitter plate. Plate lengths of $2 \%, 5 \%$, and $7.5 \%$ all appeared to produce additional smaller vortices at the edges of the splitter with signs opposite that of the vortex of the corresponding upper or lower surface. The smaller splitter plates continue to allow flow to reciprocate and form pockets of low pressure at the trailing edge. FIGURE 25 displays pressure coefficient contours for the flat back airfoil and flat back airfoil with $10 \%$ chord 
trailing edge length. Pressure is increased along the pressure side of the airfoil using the splitter plate and low pressure vortical structures are reduced in magnitude using a splitter plate. Flow still becomes trapped at the trailing edge as evidenced by the reciprocating streamlines. It does appear that vorticity is still shed by both FIGURE 24 and FIGURE 25.

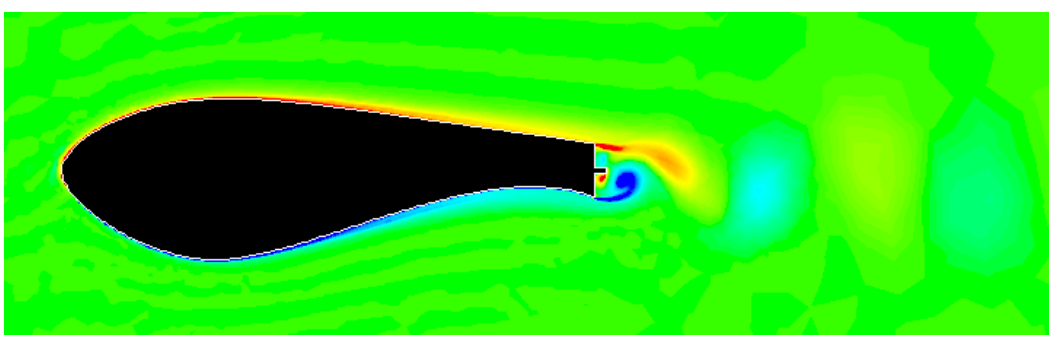

a.

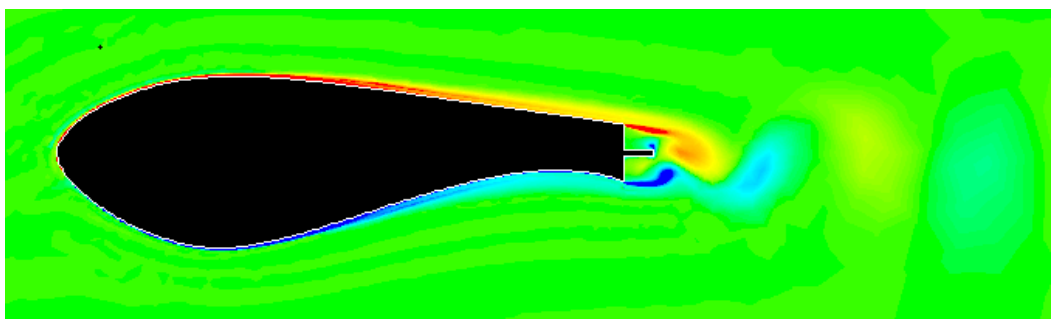

b.

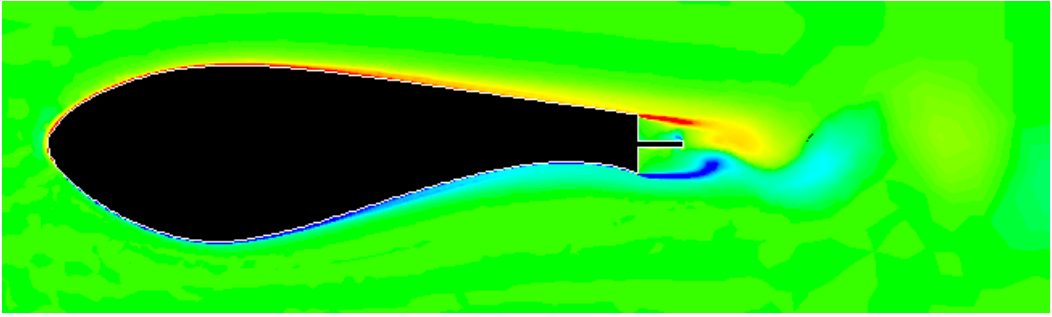

c.

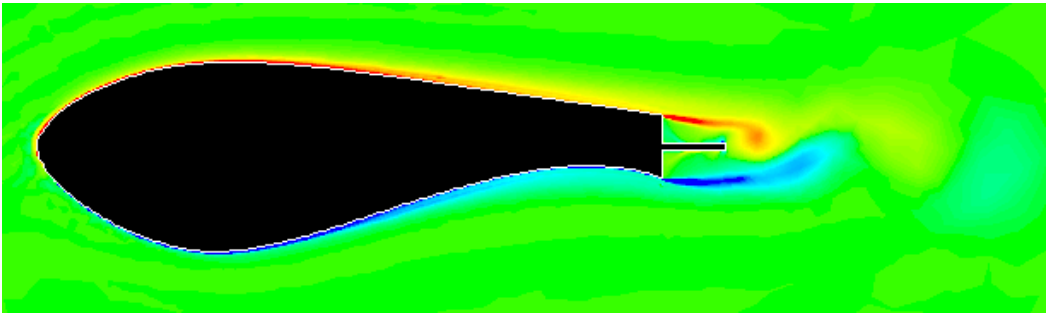

d.

FIGURE 24- Vorticity contours, two equation model, a. 2\% chord splitter length, b. 5\% chord splitter length, c. $7.5 \%$ chord splitter length, d. $10 \%$ chord splitter length, 6.18 AOA 


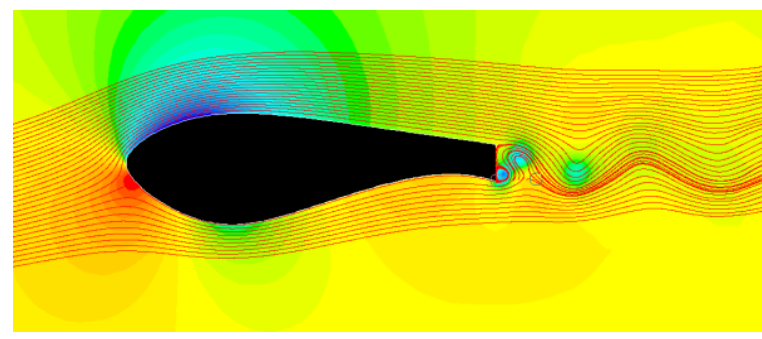

a.

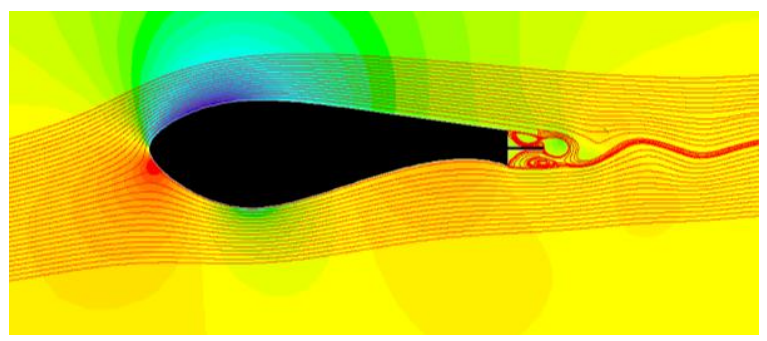

b.

FIGURE 25 - Pressure coefficient contours with streamlines, two equation model, 6.18 AOA, a. flat back airfoil, b. $10 \%$ chord splitter plate length

The three equation $k-\omega$ transition model, despite its agreement with the two equation model in the prediction of drag reduction, predicts no vortex shedding with the addition of the splitter plate to the airfoil. This is in agreement with Baker et al (2008) who determined numerically that the addition of a splitter plate would eliminate the emission of vortical wake structures from the trailing edge of the blunt airfoil. In FIGURE $26 \mathrm{~b}$ the flow is seen still captured yet there is no emission of vortical flow from the splitter plate as seen in FIGURE 25 b.

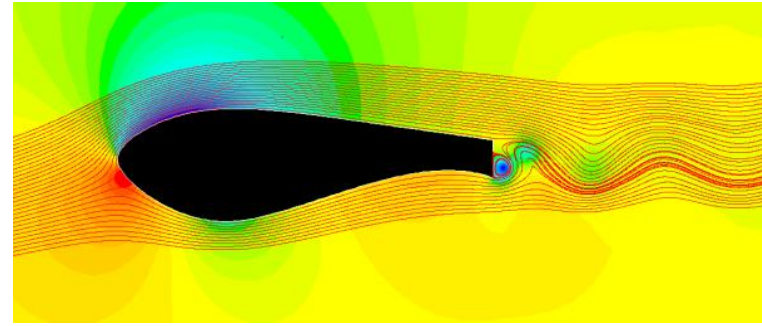

a.

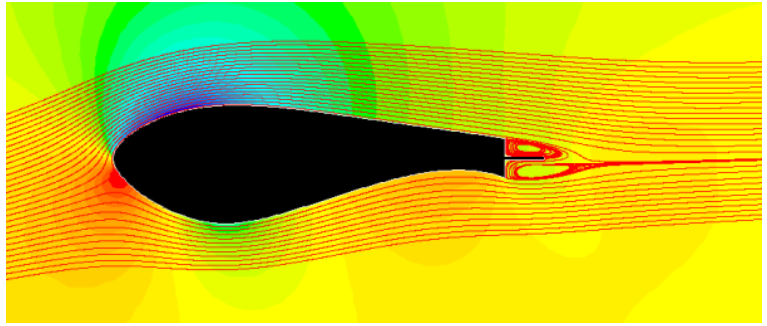

b.

FIGURE 26- Pressure coefficient contours with streamlines, three equation model, 6.18 AOA, a. flatback airfoil, b. $10 \%$ chord splitter plate length

The decrease in drag illustrated by FIGURE 22 and FIGURE 23 can be explained further by the airfoil surface pressure plots of FIGURE 27. The greatest effect is seen when using the two equation $k-\omega$ model and splitter plate. The overall base pressure is very similar to the airfoil with no splitter yet the suction pressure is reduced using the splitter. 
The overall pressure gradient at the trailing edge is therefore slightly reduced resulting in a decrease in drag coefficient.

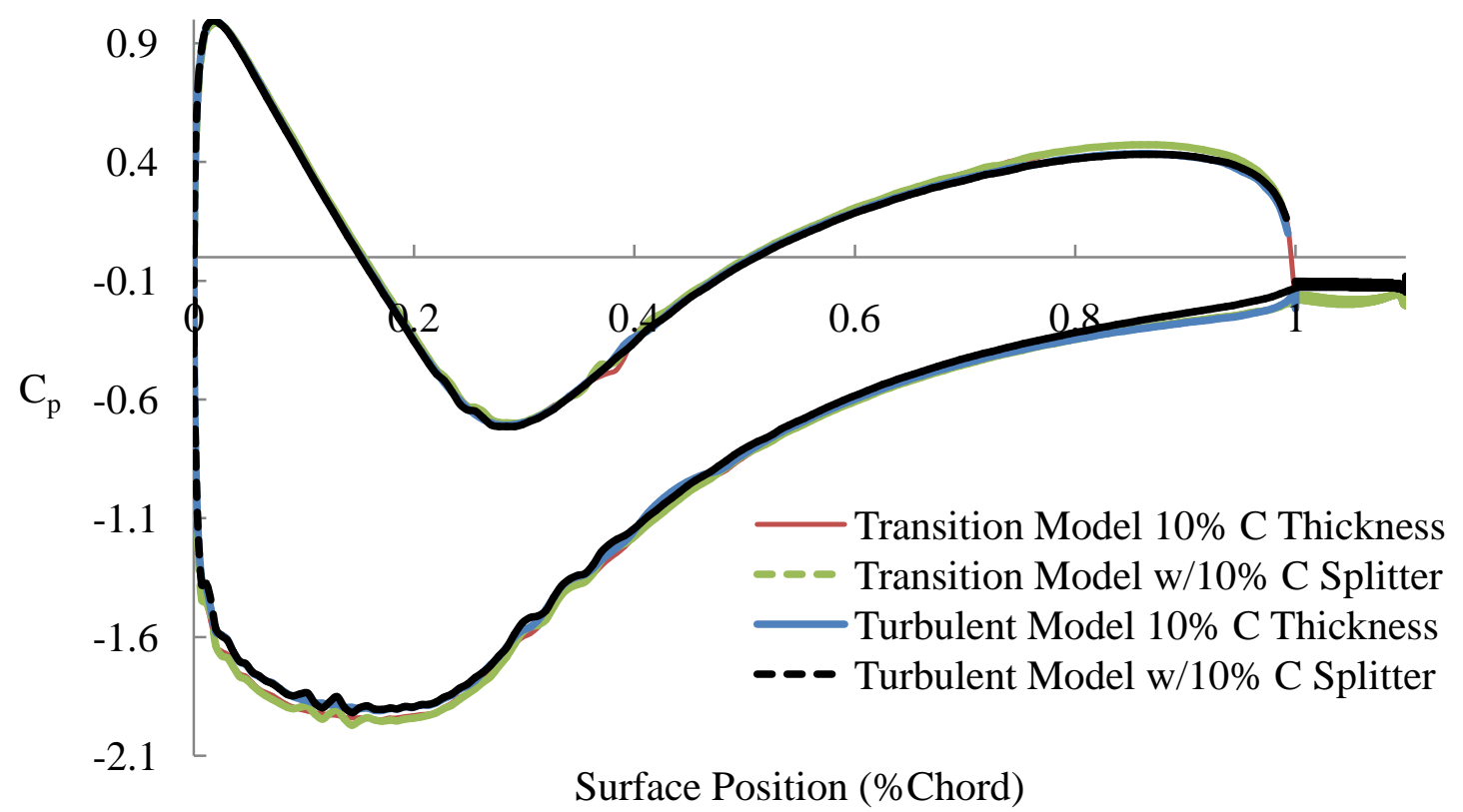

FIGURE 27 - Airfoil surface coefficient of pressure values flatback vs. flatback w/ 10\% C splitter length, 6.18 AOA 


\section{Study of Aerodynamically Induced Noise}

As presented by Berg et al (2008) the blunt trailing edge airfoil is prone not only to increased drag but to increased aerodynamic noise. The increased noise is due primarily to the vortex shedding phenomenon associated with the bluff body wakes (Berg et al 2008) as shown in FIGURE 19, FIGURE 24, FIGURE 25, and FIGURE 26. It has been predicted that the vortex shedding noise will be contained in the relatively low frequency band of 50-200 Hz and the noise could be tonal in nature (Berg et al 2008). In an attempt to predict the aerodynamic noise produced from a flat back airfoil and compare it with noise from an identical airfoil employing trailing edge modifications as previously presented, the aerodynamically generated noise will be predicted using the Ffowcs Williams and Hawkings model in Ansys Fluent 12. It is an inhomogeneous wave equation derived by manipulating the continuity equation and Navier-Stokes equations. The equations for this model are derived in APPENDIX I. The model is used by first calculating a time-accurate flow solution with time histories of pressure, velocity, and density followed by calculating sound pressure signals at receiver locations specified by the user.

The two equation $k$ - $\omega$ turbulence model is used for these unsteady simulations with a time step sufficiently small to obtain a frequency range of $0-10 \mathrm{kHz}$. The source correlation length required by Fluent to model the acoustic emission source as a volume was specified as the chord length of the airfoil. Acoustic analyses are inherently computed in three dimensional space and as such a unit of depth must be specified when performing acoustic analysis in two dimensional space. As this source correlation is 
simply an estimation 2-d aero acoustic simulations will only be used to predict trends in the data. The resolution of the acoustic data is $2 \mathrm{~Hz}$ corresponding with an unsteady calculation time of 0.5 seconds.

The $1.74 \%$ trailing edge thickness airfoil, $10 \%$ trailing edge thickness airfoil, and the $10 \%$ trailing edge thickness airfoil with splitter plate were all simulated and acoustic sound pressure data obtained. In accordance with Berg et al (2008) the sound pressure level receiver was specified as shown in FIGURE 28. The unsteady simulation results were shifted from the time domain to the frequency domain using the Fast Fourier Transform feature of Ansys Fluent 12. Its derivation is shown in APPENDIX II. The frequency spectrum data displayed will be limited to $0-500 \mathrm{~Hz}$ and will report sound pressure level $(\mathrm{dB})$ as a function of frequency. This plot is shown in FIGURE 29.

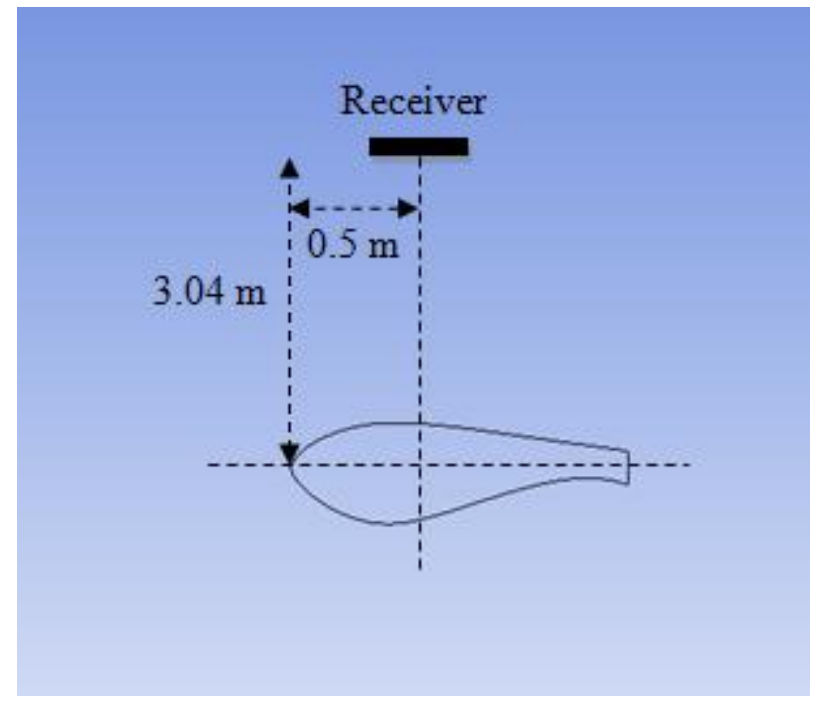

FIGURE 28 - Aero-acoustic simulation sound pressure level receiver location The trends shown in FIGURE 29 predict a peak sound pressure level around $100 \mathrm{~Hz}$ for both the $10 \%$ trailing edge thickness airfoil with and without splitter plate. The model predicts a substantial decrease in sound pressure level with the addition of the splitter 
plate. There is appreciable sound pressure level spectrum shown for the relatively thin $1.74 \%$ thickness trailing edge airfoil. This is likely due to the lack of vortex shedding as displayed in FIGURE 14. Clearly the trend though is to a reduction of low frequency sound pressure level emission from the blunt trailing edge airfoil by the use of a splitter plate.

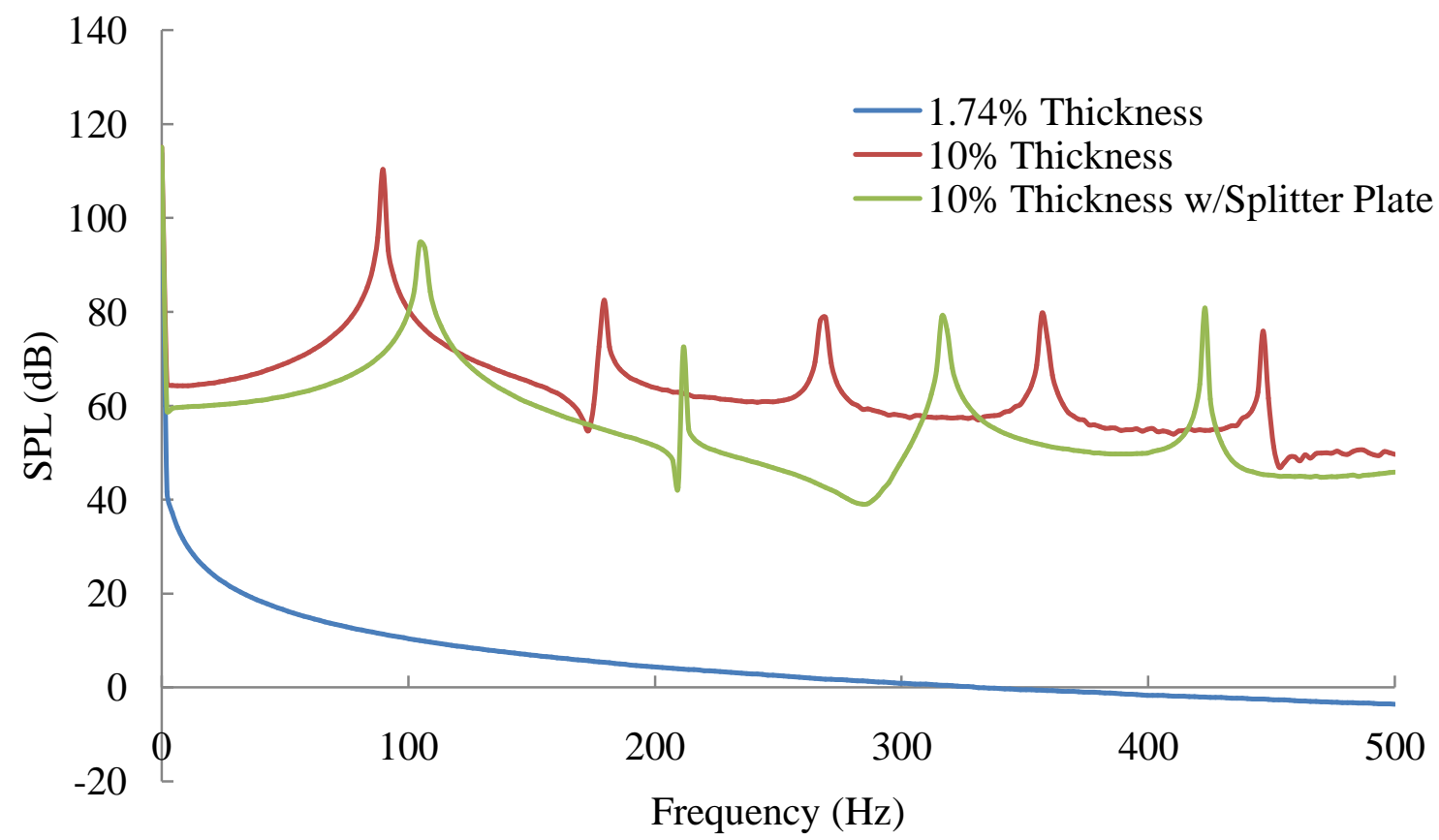

FIGURE 29 - Low frequency band sound pressure level, 6.18 AOA 


\section{CONCLUSIONS}

The results from the computational fluid dynamics analyses of the preceding chapters show that aerodynamically generated lift can be increased by thickening the trailing edge of the airfoil and that trailing edge modifications such as a splitter plate can effectively reduce the drag incurred by the thicker trailing edge. It was shown that grid sensitivity analyses allow numerical optimization of fluid flow solutions. An extraordinarily high grid density was shown to not be necessary when the flow field can be represented by a much smaller mesh density. Additionally both unstructured and hybrid grids were created to evaluate the corresponding aerodynamic performance of either grid technique. It was determined that there is a negligible difference in solution when comparing an unstructured and hybrid grid. A hybrid grid provides a slight computational efficiency increase due to the efficiency with which computational methods can be applied to quadrilateral grids. The unstructured grid allowed more complex geometry that the hybrid grid could not map.

It was found that by thickening the trailing edge of the airfoil from $1.74 \%$ of the chord length to $10 \%$ of the chord length both the Wilcox (2006) $k$ - $\omega$ turbulence model 
and the $k-\omega-k_{l}$ turbulence transition model predicted an increase in the lift generation of the airfoil at angles of attack ranging from 2 to 10 degrees. Both models also predict a drastic increase in drag. The three equation turbulence transition model predicts a lower increase in drag than does the two equation Wilcox (2006) turbulence model at all angles of attack tested. The addition of a splitter plate to the blunt trailing edge of the thick airfoil is shown to reduce drag at all angles of attack. Varying the plate length from $2 \%$ of the trailing edge width to $10 \%$ of the trailing edge width demonstrated that as splitter length increases drag reduction increases. Both the two equation Wilcox (2006) and the three equation transition turbulence model predict that a splitter plate with length equal to trailing edge thickness demonstrates the greatest reduction in lift. Airfoil surface pressure distributions explained the decrease in the base drag exhibited by the thick airfoil with splitter plate trailing edge treatment. The splitter plate serves to address the adverse pressure gradient.

The characteristic low tonal noise of the blunt trailing edge airfoil was shown in FIGURE 29. This aerodynamically generated noise plays a huge role in the acceptance of these type of airfoils for use on wind turbines. The low frequency and tonal nature of the noise can be perceived as very annoying (Berg et al 2008). Use of two dimensional simulations to characterize noise emissions is inherent with some uncertainty but it has been shown that the use of trailing edge modifications such as the splitter plate can reduce in amplitude the tonal noise produced by the blunt trailing edge airfoil.

This study is limited in its adoption of two dimensional models to simulate inherently three dimensional flow structures that are present from the airfoil. 
Additionally the relative uncertainty to predict the laminar to turbulent transition and the method by which the three equation turbulence transition model predicts turbulence is not known. The research is however useful to predict the extent to which design devices such as splitter plates on blunt trailing edge airfoils have upon the aerodynamic and aero acoustic properties of the airfoils. 


\section{APPENDIX I}

Ffowcs Williams and Hawkings Acoustics Model

$$
\begin{gathered}
\frac{1}{a_{0}^{2}} \frac{\partial^{2} \rho^{\prime}}{\partial t^{2}}-\nabla^{2} \rho^{\prime}=\frac{\partial^{2}}{\partial x_{i} \partial x_{j}}\left\{T_{i j} H(f)\right\}-\frac{\partial}{\partial x_{i}}\left\{\left[P_{i j} n_{j}+\rho u_{i}\left(u_{n}-v_{n}\right)\right] \delta(f)\right\} \\
+\frac{\partial}{\partial t}\left\{\left[\rho_{0} v_{n}+\rho\left(u_{n}-v_{n}\right)\right] \delta(f)\right\}
\end{gathered}
$$

where $u_{i}$ is the fluid velocity component in the $x_{i}$ direction, $u_{n}$ is fluid velocity component normal to the surface $f=0, v_{i}$ is the surface velocity components in the $x_{i}$

direction, $v_{n}$ is the surface velocity component normal to the surface, $\delta(f)$ represents the Dirac delta function, and $H(f)$ the Heaviside function. 


\section{APPENDIX II}

\section{Fast Fourier Transform Model}

$$
\phi_{k}=\sum_{n=0}^{N-1} \widehat{\phi}_{n} e^{2 \pi i k n / N} \quad k=0,1,2, \ldots(N-1)
$$

where $\hat{\phi}_{n}$ are discrete Fourier coefficients which are obtained from

$$
\widehat{\phi}_{n}=\frac{1}{N} \sum_{k=0}^{N-1} \phi_{k} e^{-2 \pi i k n / N} \quad n=0,1,2, \ldots(N-1)
$$

These two equations form a Fourier transform pair so one can be determined from the other. 


\section{REFERENCES}

Ashwill, Thomas D. Materials and Innovations for Large Blade Structures: Research Opportunities in Wind Energy Technology. Proc. of 50th AIAA/ASME/ASCE/AHS/ASC Structures, Structural Dynamics, and Materials Conference, California, Palm Springs. Vol. 2407. AIAA, 2009. Print.

Baker, Jonathon P., and C. P. Van Dam. DRAG REDUCTION OF BLUNT TRAILINGEDGE AIRFOILS. Proc. of BBAA VII International Colloquium On: Bluff Bodies Aerodynamics \& Applications, Milano, Italy. 2008. Print.

Balat, M. "A Review of Modern Wind Turbine Technology." Energy Sources, Part A: Recovery, Utilization, and Environmental Effects 31.17 (2009): 1561-572. Print.

Berg, Dale E., and Matthew Barone. Aerodynamic and Aeroacoustic Properties of a Flatback Airfoil (Will It Rumble or Whisper?). Proc. of WINDPOWER 2008, Houston, TX. 2008. Print.

Campbell, Colin. "Adopt the Protocol | Oil Depletion Protocol." Oil Depletion Protocol. Web. 27 Mar. 2010. <http://www.oildepletionprotocol.org/Adopt>.

Dussin, D., M. Fossati, A. Guardone, and L. Vigevano. "Hybrid Grid Generation for Two-dimensional High-Reynolds Flows." Computers and Fluids 38 (2009): 1863875. Print.

"Fast Fourier Transform." Fluent Users. Ansys Fluent 12. Web. 01 Apr. 2010. <http://www.fluentusers.com/fluent/doc/ori/v121/fluent/fluent12.1/help/html/ug/nod e953.htm>.

"The Ffowcs Williams and Hawkings Model." Fluent Users. Ansys Fluent 12. Web. 01 Apr. 2010. <http://www.fluentusers.com/fluent/doc/ori/v121/fluent/fluent12.1/help/html/th/node 236.htm>.

"The Global Wind Resource." College of Earth, Ocean, and Environment | The College of Earth, Ocean, and Environment. Web. 27 Mar. 2010. <http://www.ceoe.udel.edu/windpower/ResourceMap/index-world.html>. 
Griffith, D. Todd. Structural Dynamics Analysis and Model Validation of Wind Turbine Structures. Proc. of 50th AIAA/ASME/ASCE/AHS/ASC Structures, Structural Dynamics, and Materials Conference, Palm Springs, California. Vol. 2408. AIAA, 2009. Print.

Hallett, Michael. "Distributed power in Afghanistan: The Padisaw micro-hydro project." Renewable Energy 34 (2009): 2847-851. Print.

Hurley, Brian. "Where Does Wind Come From - And How Much Is There? |Claverton Group." Claverton Group : Experts in Energy, Environmental, Climate \& Transportation : News, Information \& Forum. 24 Oct. 2008. Web. 27 Mar. 2010. $<$ http://www.claverton-energy.com/where-does-the-wind-come-from-and-howmuch-is-there.html>.

Kaygusuz, K. "Environmental Impacts of the Solar Energy Systems." Energy Sources, Part A: Recovery, Utilization, and Environmental Effects 31.15 (2009): 1376-386. Print.

Laird, Daniel, and Thomas Ashwill. WIND ENERGY RESEARCH AT SANDIA NATIONAL LABORATORIES. Rep. 2004. Print.

McNally, Amy, Darrin Magee, and Aaron T. Wolf. "Hydro Power and Sustainability: Resilience and Vulnerability in Chinas Power sheds." Journal of Environmental Management 90 (2009): S286-293. Print.

Stone, Christopher, Matthew Barone, C. Eric Lynch, and Marilyn J. Smith. A Computational Study of the Aerodynamics and Aeroacoustics of a Flatback Airfoil Using Hybrid RANS-LES. Proc. of 47th AIAA Aerospace Sciences Meeting Including The New Horizons Forum and Aerospace Exposition, Orlando, Florida. 273rd ed. AIAA, 2009. Print.

van Dam, C. P. "Blade Aerodynamics Blade Aerodynamics - - Passive and Active Load Control for Wind Turbine Passive and Active Load Control for Wind Turbine Blades." Department of Mechanical \& Aeronautical Engineering. University of California, Davis. 2009. Lecture.

van Dam, C. P., Daniel L. Kahn, and Dale E. Berg. Trailing Edge Modifications for Flatback Airfoils. Rep. no. SAND2008-1781. Albuquerque: Sandia National Laboratories, 2008. Print.

Wilcox, David C. Turbulence Modeling for CFD. Third ed. Vol. 1. Mill Valley: Personal TEX, 2006. Print.

Winnemöller, T., and C. P. Van Dam. "Design and Numerical Optimization of Thick Airfoils Including Blunt Trailing Edges." JOURNAL OF AIRCRAFT 44.1 (2007). Print. 
MATTHEW L. FULLER

786 Raymond Kent Ct. Apt. 1

Louisville, KY 40217

(270) 3483076

matt.l.fuller@gmail.com

OBJECTIVE

EDUCATION

KEY APPLIED

EXPERIENCE

EMPLOYMENT HISTORY

SKILLS/

COURSEWORK

ACTIVITIES \& HONORS

REFERENCES
Engineering Position, Manufactured Goods Design, Production and Optimization
M. Eng. in Mechanical Engineering

B. Sc. in Mechanical Engineering

J.B. Speed School of Engineering, UofL, Louisville, KY

Dates attended September 2005 - present

High School Diploma

Hopkinsville High School, Hopkinsville, KY
Expected May 2010

August 2009

GPA 3.6/4.0

Hours Completed: 147

May 2005
Mechanical Engineering Co-op: Provided mechanical engineering support to engineers within a fast-paced manufacturing environment. With minimal direction and oversight, I assumed responsibility for affecting the functional implementation of an underutilized industrial CAD system, and I was responsible for creating and distributing internal documents including work instructions and manufacturing specification sheets.

UofL Speed School CFD Lab, Louisville, Ky (Part-time)

August 2009 - present Computational Fluid Dynamics Technician

- Employ academic and commercial fluid modeling software to describe complex airfoils;

- Evaluate wind turbine blade section design;

- Prepare master thesis of alternative turbine blade airfoil designs.

Orbis Corporation, Georgetown, KY (Part-time)

2007-2008

Mechanical Engineering Co-Op Employee

- Expand under-utilized CAD system \& design/distribute fabrication work instructions;

- Provide technical support to professional mechanical engineering staff.

Airtight Insulation, Hopkinsville, KY

Summers 2003-2005 Insulation Technician

- Weather sealed inner and outer surfaces of houses;

- Fire-proofed all electrical wires passing through wall studs;

- Manually operated cellulose spraying equipment;

- Excelled at showing up on time, meeting responsibilities, and following orders.
- Dassault SolidWorks;

- ICEM Finite Mesh Tool;

- Matlab;

- Composite Materials;
- Fluent Fluid Solver;

- Overture CFD Tools;

- Machine Design;

- Material Science.
Additional Miscellaneous Technical Skills

- Highly-skilled in motorcycle maintenance and repair;

- Skilled in automotive diagnosis \& repair.

- Received B. Sc. in Mechanical Engineering with "High Honors";

- Recipient Trustee's Presidential Scholarship, UofL;

- Selected for UofL Speed Scientific School Leadership Advantage; July 2005

- Graduated Hopkinsville High School "With Honors"; $\quad$ May 2005

- Attended Murray State University Commonwealth Honors Academy; June 2004

- Student Member of ASME;

- Student Member of SAE.

September 2006

September 2006

Furnished upon request. 